\title{
Beta-Adrenergic Blockade in Critical Illness
}

\author{
Rebecca Bruning ${ }^{1}$, Hannah Dykes ${ }^{1}$, Timothy W. Jones ${ }^{1}$, Nathaniel B. Wayne ${ }^{2}$ and \\ Andrea Sikora Newsome ${ }^{1 *}$
}

${ }^{1}$ Department of Clinical and Administrative Pharmacy, University of Georgia College of Pharmacy, Augusta, GA, United States, ${ }^{2}$ Department of Pharmacy, Augusta University Medical Center, Augusta, GA, United States

Catecholamine upregulation is a core pathophysiological feature in critical illness. Sustained catecholamine $\beta$-adrenergic induction produces adverse effects relevant to critical illness management. $\beta$-blockers $(\beta B)$ have proposed roles in various critically ill disease states, including sepsis, trauma, burns, and cardiac arrest. Mounting evidence suggests $\beta \mathrm{B}$ improve hemodynamic and metabolic parameters culminating in decreased burn healing time, reduced mortality in traumatic brain injury, and improved neurologic outcomes following cardiac arrest. In sepsis, $\beta \mathrm{B}$ appear hemodynamically benign after acute resuscitation and may augment cardiac function. The emergence of ultra-rapid $\beta \mathrm{B}$ provides new territory for $\beta \mathrm{B}$, and early data

OPEN ACCESS

Edited by: Mahmoud El-Mas, Alexandria University, Egypt

Reviewed by: Folke Bror Sjoberg, Linköping University Hospital, Sweden Samuel Tisherman University of Maryland, United States

${ }^{*}$ Correspondence: Andrea Sikora Newsome sikora@uga.edu

Specialty section: This article was submitted to Cardiovascular and Smooth Muscle Pharmacology, a section of the journal Frontiers in Pharmacology

Received: 03 July 2021 Accepted: 27 September 2021

Published: 15 October 2021

Citation:

Bruning $R$, Dykes $H$, Jones TW, Wayne NB and Sikora Newsome A (2021) Beta-Adrenergic Blockade in

Critical Illness.

Front. Pharmacol. 12:735841. doi: 10.3389/fphar.2021.735841 suggest significant improvements in mitigating atrial fibrillation in persistently tachycardic septic patients. This review summarizes the evidence regarding the pharmacotherapeutic role of $\beta \mathrm{B}$ on relevant pathophysiology and clinical outcomes in various types of critical illness.

Keywords: beta-blockers, critical illness, sepsis, esmolol, tachyarrhythmia, hemodynamics

\section{INTRODUCTION}

The catecholamine cascade is a defining element of critical illness (Preiser et al., 2014). The $\alpha$ - and $\beta$-adrenergic receptors form the response mechanism for endogenous catecholamines and exogenously administered catecholamine vasoactive agents (e.g., dobutamine, dopamine, norepinephrine, and epinephrine) (Preiser et al., 2014). These receptors elicit responses in nearly every major organ system and change their expression levels during the body's stress response to critical illness (Belletti et al., 2020). Prolonged exposure to high levels of catecholamines in these altered states may evoke detrimental metabolic and hemodynamic effects. Higher levels of catecholamines appear in a myriad of critical illness etiologies and have been associated with higher mortality (Tripathi et al., 1981; Hamill et al., 1987; Benedict and Rose, 1992; Boldt et al., 1995; Dunser and Hasibeder, 2009).

$\beta$-blockers $(\beta B)$ may be administered to manipulate the adrenergic response during critical illness. $\beta \mathrm{B}$ are mainstay medications for cardiovascular disease states, including post-myocardial infarction management (O'Gara et al., 2013), atrial fibrillation (AF) (January et al., 2014), and heart failure (HF); however, evaluation of the utility of $\beta \mathrm{B}$ extends beyond long-term cardiac management into acute management of critically ill patients (Writing et al., 2021). The purpose of this review is to critically evaluate available literature regarding $\beta B$ therapy in critical illness and describe evidencebased $\beta B$ use in presentations of critical illness including sepsis, severe burns, traumatic brain injury, and cardiac arrest. 
TABLE 1 | Dosing and timing of $\beta B$ in critical illness.

\begin{tabular}{llll}
\hline Sepsis & Population & $\boldsymbol{\beta}$-Blockade & Initiation \\
\hline Study & & & \\
\hline Schmittinger et al. & 40 patients with septic shock & Metoprolol 25-47.5 mg PO & Initiated only after stabilization of \\
(2008) Retrospective & and cardiac depression & $\begin{array}{l}\text { Increased gradually to achieve } \\
\text { target HR (65-95 bpm) }(\mathrm{n}=40)\end{array}$ & $\begin{array}{l}\text { cardiovascular function }(17.7 \pm \mathrm{h} \text { after shock onset or ICU } \\
\text { admission) }\end{array}$
\end{tabular}

\begin{tabular}{lll}
\hline Gutierrez et al. (2009) 83 septic patients & Any $\beta$ B exposure $(n=54)$ vs. no Not reported \\
Retrospective & $\begin{array}{l}\text { exposure }(n=29) \text { Dosing not } \\
\text { reported }\end{array}$
\end{tabular}

Any $\beta$ B exposure $(n=54)$ vs. no Not reported
exposure $(n=29)$ Dosing not reported

HR control was achieved in $97.5 \%$ of patients $(n=39)$ within $12.2 \pm$ $12.4 \mathrm{~h} \mathrm{HR}, \mathrm{CVP}$, and norepinephrine, vasopressin, and milrinone dosages decreased (all $p<0.001) \mathrm{Cl}$ remained unchanged whereas SVI increased $(p=0.002)$

Berk et al. (1972) Case 26 patients with refractory series $\mathrm{Hg}$ and $\mathrm{UOP}<12 \mathrm{ml} / \mathrm{h}$
Propranolol $5 \mathrm{mg}$ given over 2-3 h Approximately 24-48 h from start of period followed by another $5 \mathrm{mg}$ during the next $6-12 \mathrm{~h}(\mathrm{n}=11)$
Approximately $24-48 \mathrm{~h}$ from start of conventional interventions (fluids, antibiotics, steroids)

$\beta B$ not significantly associated with mortality in the univariate $(\mathrm{OR}=$

1.83 ; $95 \% \mathrm{Cl}=0.59-5.69$ ) nor multivariate model $(\mathrm{OR}=1.843$; 95\% $\mathrm{Cl}=0.56-6.10$ )

Increased $\mathrm{BP}, \mathrm{PaO} 2$, urinary output, and total peripheral resistance in before and after propranolol use case series Decreased CVP, CO, and HR Sunvival resulted in the 8 who had a normal or increased $\mathrm{CO}$ prior to $\beta B$. The 3 who did not survive had very low CO

\begin{tabular}{llll}
\hline Gore and Wolfe (2006) & 6 moderately septic, & Esmolol infusion to target 20\% HR & Infusion started immediately \\
Prospective & $\begin{array}{l}\text { mechanically ventilated patients } \\
\text { with pneumonia }\end{array}$ & $\begin{array}{l}\text { reduction (range: } 6-22 \mathrm{mg} / \\
\min )(\mathrm{n}=6)\end{array}$ & following $5 \mathrm{~h}$ basal measurements
\end{tabular}

Significant decrease in $\mathrm{Cl} p<$ $0.05)$ proportional to decrease in HR $(p<0.05)$ No significant difference in SVR, SVI, BP, extremity/hepatic blood flow, REE, oxygen consumption

Balik et al. (2012) 10 septic patients

Prospective
Esmolol bolus $(0.2-0.5 \mathrm{mg} / \mathrm{kg})$ followed by continuous $24 \mathrm{~h}$ infusion with titration to achieve $20 \%$ decrease of baseline HR $(n=10)$
After correction of preload ( $2 \mathrm{~h}$ after sepsis)

HR decreased from mean $142 \pm$ $11 /$ min to $112 \pm 9 / \min (p<0.001)$ Insignificant reduction of $\mathrm{Cl}(4.94 \pm$ 0.76 to $4.35 \pm 0.72 \mathrm{~L} / \mathrm{min} / \mathrm{m} 2)$. SV insignificantly increased. No significant changes of norepinephrine infusion $(0.13 \pm$ 0.17 to $0.17 \pm 0.19 \mu \mathrm{g} / \mathrm{kg} / \mathrm{min}$, $\mathrm{DO} 2, \mathrm{VO} 2, \mathrm{OER}$ or arterial lactate

Decreased HR Decrease in Ea Decreased SV (all $p<0.05$ ) CO, EF unchanged NE requirements were reduced $(p<0.05)$

$\mathrm{HR}$ reached target within $72 \mathrm{~h}$ for both treatment groups $\mathrm{ScvO} 2$ increased in the esmolol group and decreased in the control group $(p<$ 0.01). Lactate reduction in control group at $48 \mathrm{~h}(\mathrm{p}<0.05)$ Shorter duration of mechanical ventilation in the esmolol group $(p<0.05)$
Du et al. (2016) Prospective
63 patients with septic shock within $48 \mathrm{~h}$ of diagnosis
Esmolol $20 \mathrm{mg}$ loading dose following by $25 \mathrm{mg} / \mathrm{h}$ infusion to achieve HR reduction by $10-15 \%$ from baseline $(n=63)$
Hemodynamically stable with $\mathrm{HR} \geq$ $100 \mathrm{bpm}<48 \mathrm{~h}$ after septic shock started
$\mathrm{BP}$ was unaltered $\mathrm{SV}$ was increased compared with before esmolol therapy $(43.6 \pm 22.7$ vs. $49.9 \pm 23.7 \mathrm{ml} ; p=0.047)$ Decreased lactate levels $(1.4 \pm 0.8$ vs. $1.1 \pm 0.6 \mathrm{mmol} / \mathrm{L} ; p=0.015$ )

Decreased HR-28 bpm [IQR -7-21; $p<0.001]$ Decreased $20 \mathrm{~min}$ to reach target HR $80-94$ bpm) $(n=77)$ vs control $(n=77)$
Initiated after randomization that was performed after resuscitation with fluid and vasopressors for $24 \mathrm{~h}$
Morelli et al.

(2013) RCT
154 septic patients
NE requirement -0.01 [IQR $-0.2-0.44 ; p=0.003]$ Decreased 28 -days mortality 49.4 vs. $80.5 \%$ $(p<0.001)$

(Continued on following page) 
TABLE 1 | (Continued) Dosing and timing of $\beta \mathrm{B}$ in critical illness.

\begin{tabular}{llll}
\hline Sepsis & Population & $\beta$-Blockade & Initiation \\
\hline
\end{tabular}

Study

Yang et al. (2014) RCT 41 septic patients

Wang et al. $\quad 90$ septic patients

(2015) RCT

Esmolol + milrinone $(n=30)$ vs

milrinone $(n=30)$ vs. control

$(n=30)$ Dosing not reported

Esmolol 0.05 mg/kg/min (adjusted to achieve HR of $<100 \mathrm{bpm}$ in $2 \mathrm{~h}$ ) $(n=21)$ vs. control $(n=20)$

Initiated after randomization that

was performed after 6-h

resuscitation with fluid and

vasopressors

Not reported
Xinqiang et al. $\quad 48$ septic patients

(2015) RCT
Esmolol 0.05 mg/kg/min (adjusted to achieve HR of $<100 \mathrm{bpm}$ within 24 h) $(n=24)$ vs. control $(n=24)$
Initiated after randomization that was performed after resuscitation with fluid and vasopressors for $6 \mathrm{~h}$

Wang et al. $\quad 76$ septic patients
(2017) RCT

Liu et al. (2019) RCT 100 septic patients
Esmolol 25 mg/h (titrated every 20 min to reach the HR between 80 and 100/min within 12 h) ( $\mathrm{n}=$ $50)$ vs control $(n=50)$
Esmolol $0.05 \mathrm{mg} / \mathrm{kg} / \mathrm{hr}$ (titrated every 5 min to reach the HR of $<95 /$ min within 4 h) $(n=30)$ vs. control $(n=30)$
Initiated after randomization that was performed after resuscitation with fluid and vasopressors for $24 \mathrm{~h}$

Initiated after randomization that was performed after being resuscitated with fluid and vasopressors for $24 \mathrm{~h}$
Decreased HR $12 \mathrm{~h}(93 \pm 4 ; p<$ 0.05); Decreased Cl (3.3 $\pm 0.8 ; p<$ $0.05)$ No significant changes in MAP, CVP, or SVI ScVO2 was not decreased

100\% HR control (74-94 bpm) within $96 \mathrm{~h}$ of initiation $(p<0.001$ vs. milrinone) Increased 28-days survival 60 vs. $33.3 \%$ (milrinone) vs. $26.7 \%$ (control) Decreased NE use $0.07 \pm 0.04$

Decreased LOS $(13.75 \pm 8.68$ vs. $21.7 \pm 6.06 ; p<0.001)$ Decreased 28 -days mortality (25.0 vs. $62.5 \%$; $p<0.009$ ) Decreased HR, arterial lactate levels Increased SVRI, SVI, ScVO2 (all $p<0.01$ )

HR decreased significantly at each time point No significant difference in MAP Cl significantly increased at $>24 \mathrm{~h} \mathrm{SVI}$ significantly increased at $>4 \mathrm{~h}$ No difference in 28-days mortality ( 30 vs. $36.7 \% ; p=0.583$ )

No difference in 28-days mortality (62 vs 68\%; $p=0.529$ ) Lower HR on day $1-7$; but overall no statistically significant difference in HR $(p>0.05)$ No significant difference in total does of NE, lactate level, inflammatory markers, APACHEII, SOFA, hospital LOS (all $p>0.05$ )

\begin{tabular}{lll}
\hline Kakihana et al. & 151 septic patients with HR > & Landiolol $1 \mu \mathrm{g} / \mathrm{kg} / \mathrm{min}$ (titrated \\
(2020) RCT & 100 bpm and diagnosis of atrial & every $15-20 \mathrm{~min}$, until the HR \\
& $\begin{array}{ll}\text { fibrillation, atrial flutter, or sinus } \\
\text { tachycardia }\end{array}$ & $\begin{array}{l}\text { decreased to less than } 95 \mathrm{bpm}) \\
(\mathrm{n}=76) \mathrm{vs} . \text { control }(\mathrm{n}=75)\end{array}$
\end{tabular}
$\begin{array}{ll}\text { fibrillation, atrial flutter, or sinus } & \text { decreased to less than } 95 \text { bp } \\ \text { tachycardia } & (n=76) \text { vs. control }(n=75)\end{array}$ Landiolol was initiated within $2 \mathrm{~h}$ after randomization that was conducted after being resuscitated with fluid and vasopressors (mean time from ICU admission to randomization: $15.8 \mathrm{~h}$ in landiolol vs. $13.5 \mathrm{~h}$ in control)
Larger proportion of patients had HR 60-94 bpm $24 \mathrm{~h}$ after randomization ( $55 \%$ [ 41 of 75 ] vs. $33 \%$ [25 of 75$]$ ), with a betweengroup difference of $23.1 \%(95 \% \mathrm{Cl}$ 7.1-37.5; $p=0.0031$ ) Decreased incidence of new-onset arrhythmia by $168 \mathrm{~h}(9$ vs. $25 \% ; p=0.015)$ No significant difference in 28-days mortality $(p=0.22)$, hospital free days $(p=0.91)$, ICU free days $(p=$ $0.55)$, and ventilator free days $(p=0.47)$

$\beta \mathrm{B}$ were associated with lower hospital mortality when compared with CCBs $(n=18,720$; relative risk $[\mathrm{RR}]=0.92 ; 95 \% \mathrm{Cl}=0.86-0.97)$, digoxin $(n=13,994$; $R R=0.79$; $95 \% \mathrm{Cl}=0.75-0.85)$, and amiodarone $(n=5,378 ; R R=0.64$; $95 \% \mathrm{Cl}=0.61-0.69)$ Results were similar among subgroups with new-onset or preexisting AF, heart failure, vasopressor-dependent shock, or hypertension 
TABLE 1 | (Continued) Dosing and timing of $\beta B$ in critical illness.

\begin{tabular}{|c|c|c|c|c|}
\hline Sepsis & Population & $\beta$-Blockade & Initiation & Outcome \\
\hline
\end{tabular}

Study

Bosch et al. (2020) Retrospective
666 septic patients with atrial fibrillation with rapid ventricular response
CCB $(n=225)$ vs. $\beta B$ (IV metoprolol or esmolol; $n=67$ ) vs. amiodarone $(n=337)$ vs. digoxin $(n=37)$
Amiodarone and CCB added within 1-2 $\mathrm{h}$ of start of atrial fibrillation vs $4.9 \mathrm{~h}$ for digoxin vs. $10.2 \mathrm{~h}$ for $\beta \mathrm{B}$

\section{Macchia et al. (2012) 9,465 septic patients} Retrospective
Chronic outpatient $\beta B(n=1,061)$ vs. no previous $\beta B$ treatment $(n=$ $8,404)$
N/A Pre-morbid $\beta B$
The adjusted hazard ratio for $\mathrm{HR}$ of $<110$ beats/min by $1 \mathrm{~h}$ was 0.50 $(95 \% \mathrm{Cl}=0.34-0.74)$ for amiodarone vs. $\beta \mathrm{B}, 0.37(95 \% \mathrm{Cl}=$ $0.18-0.77)$ for digoxin vs. $\beta B$, and $0.75(95 \% \mathrm{Cl}=0.51-1.11)$ for CCB vs. $\beta B$

Lower mortality at 28 days (188/ $1,061[17.7 \%])$ than those previously untreated $(1857 / 8,404$ [22.1\%]) $(\mathrm{OR}=0.78 ; 95 \% \mathrm{Cl}=$ $0.66-0.93 ; p=0.005$ )

Continuation of $\beta B$ therapy was significantly associated with decreased hospital $(p=0.03)$, 28days $(p=0.04)$ and 90 -days mortality rates (40.7 vs. $52.7 \%$; $p=$ 0.046)

Singer et al. (2017) 6,839 septic patients Retrospective
296 septic patients with chronic $\beta \mathrm{B}$ treatment

(secondary analysis)
Continuation of $\beta \mathrm{B}$ during acute phe of sepsis ( $n=167)$ vs. discontinuation during sepsis ( $n=129)$
Acute phase of sepsis defined as 2 days before to 3 days after disease onset
Decreased mortality during hospitalization (24 vs 31\%; $p<$ $0.0001)$ Multivariable logistic regression models 31\% decrease in in-hospital mortality (adjusted $\mathrm{OR}=0.69 ; \mathrm{Cl}=0.62-0.77$ ) Decreased 30-days mortality (13 vs. $18 \% ; p<0.0001$ )

\begin{tabular}{lll}
\hline Guz et al. (2021) & 1,186 septic patients & Chronic outpatient $\beta B(n=320)$ vs \\
Prospective & no previous $\beta$ B treatment $(n=866)$
\end{tabular}

No significant difference in crude 30-days and 90-days mortality rates (30 days, 15 vs $19 \%$ [ $p=$ 0.25 ]; 90 days, 22 vs $24 \%$ [ $p=$ 0.51]) Reduction in 30-days mortality rates for patients with absolute tachycardia $(\mathrm{OR}=0.406$; 95\% Cl $=0.177-0.932$ ) 30-days survival benefit in the subgroup of patients with relative tachycardia in both univariate and multivariate analysis $(\mathrm{OR}=0.496 ; 95 \% \mathrm{Cl}=$ $0.258-0.955 ; p=0.04$ )

\section{Burns \\ Study}

Baron et al. (1997) Prospective
Population

22 pediatric burn patients (>40\% of TBSA)
Beta-blockade

Propranolol 0.5-1 mg/kg PO or IV $\mathrm{Q} 8 \mathrm{~h}$ for 10 days $(\mathrm{n}=22)$

\section{Initiation}

During the catecholamine-induced hypermetabolic phase

$\begin{array}{ll}\text { Herndon et al. } & 25 \text { pediatric burn patients } \\ \text { (2001) } R C T & (>40 \% \text { of TBSA })\end{array}$

Jeschke et al. (2007) RCT
245 pediatric burn patients $(>40 \%$ of TBSA)
Propranolol 0.33 mg/kg/4 h through NGT ( $n=13$ ) vs. control ( $n=12$ ) (dose later adjusted for $H R$ $20 \%$ less than basal)

Propranolol $0.5-1.5 \mathrm{mg} / \mathrm{kg} / 6 \mathrm{~h} \mathrm{PO}$ $(n=102)$ vs. control $(n=143)$
Propranolol was initiated immediately following the second staged grafting procedure (approximately 8-12 days after initial admission)

Started after 7 days

\section{Outcome}

Propranolol use significantly decreased daily average $H R$ (10-13\%) and RPP (10-16\%) compared to 24-h mean pretreatment

Propranolol decreased HR $(p=$ $0.001)$ decreased REE $(p=0.001)$, oxygen consumption ( $p=0.002$ ), and prevented lean mass loss $(p=0.01)$

No significant difference between groups in terms of mortality (5 vs. $6 \%$ ), incidence of infections (21 vs. $30 \%$ ), or sepsis (7 vs. $10 \%$ ) Decreased REE $(p<0.05)$ 
TABLE 1 | (Continued) Dosing and timing of $\beta B$ in critical illness.

\begin{tabular}{|c|c|c|c|c|}
\hline Sepsis & Population & $\beta$-Blockade & Initiation & Outcome \\
\hline
\end{tabular}

Study

$\begin{array}{ll}\text { Herndon et al. } & 179 \text { pediatric burn patients } \\ \text { (2012) } R C T & (>30 \% \text { of TBSA })\end{array}$

Herndon et a $(>30 \%$ of TBSA)
Propranolol dose required to reduce $\mathrm{HR} 15 \%$ (mean dose $4 \mathrm{mg} / \mathrm{kg} /$ day $\mathrm{PO})(\mathrm{n}=90) \mathrm{vs}$ control $(n=89)$
Propranolol started $3 \pm 2$ days after admission

\begin{tabular}{lll}
\hline Williams et al. & 406 pediatric burn patients & Propranolol $1 \mathrm{mg} / \mathrm{kg} /$ day PO \\
(2011) RCT & (>30\% of TBSA) & (divided Q $6 \mathrm{~h}$; adjusted for HR \\
& $15-20 \%$ less than basal) $(\mathrm{n}=171)$ \\
& vs. control $(\mathrm{n}=235)$
\end{tabular}

From 24 to $72 \mathrm{~h}$ until end of admission (once patients were fluid stabilized)

\begin{tabular}{|c|c|c|}
\hline $\begin{array}{l}\text { Arbabi et al. (2004) } \\
\text { Retrospective }\end{array}$ & $\begin{array}{l}129 \text { adult burn patients (mean } \\
\text { TBSA } 14 \pm 12 \% \text { ); } 21 \text { pre- } \\
\text { hospital } \beta \text { B vs } 22 \text { hospital } \beta \text { B vs. } \\
86 \text { control }\end{array}$ & $\begin{array}{l}\text { Metoprolol, atenolol, esmolol, } \\
\text { labetalol, or propranolol (at } \\
\text { therapeutic doses) }\end{array}$ \\
\hline $\begin{array}{l}\text { Mohammadi et al. } \\
\text { (2009) RCT }\end{array}$ & $\begin{array}{l}79 \text { adult burn patients ( } 20-50 \% \\
\text { of TBSA) }\end{array}$ & $\begin{array}{l}\text { Propranolol } 1 \mathrm{mg} / \mathrm{kg} / \mathrm{d} \text { and max } \\
\text { dose of } 1.98 \mathrm{mg} / \mathrm{kg} / \mathrm{d} \text { given in six } \\
\text { divided doses (adjusted to achieve } \\
20 \% \text { HR reduction from baseline) } \\
\text { ( } \mathrm{n}=37 \text { ) vs. control ( } \mathrm{n}=42 \text { ) }\end{array}$ \\
\hline
\end{tabular}

All pre-hospital $\beta \mathrm{B}$ patients remained on treatment once admitted Hospital $\beta \mathrm{B}$ patients were initiated on $\beta \mathrm{B}$ a mean 8.8 days postinjury

Started on 4th day of admission after hemodynamic stabilization

\begin{abstract}
Ali et al. (2015) RCT 69 adult burn patients (>30\% of Propranolol at a dose that reduces TBSA)

HR by $20 \%$ (average dose $3.3 \pm$ $3.0 \mathrm{mg} / \mathrm{kg} /$ day) $(\mathrm{n}=35)$ vs. control $(\mathrm{n}=34)$
\end{abstract}

Administered within $48 \mathrm{~h}$ of burn and given throughout hospital stay

$\begin{array}{ll}\text { Cheema et al. } & 70 \text { adult burn patients }(20-40 \% \\ \text { (2020) RCT } & \text { of TBSA) }\end{array}$

Propranolol at dose of $0.5-3 \mathrm{mg} / \mathrm{kg} /$ day (adjusted to achieve a 20\% max HR reduction) $(n=35)$ vs. control $(n=35)$
Started on 3rd postburn day after hemodynamic stabilization
Propranolol reduces HR $(p=0.01)$, cardiac work, central body mass and trunk fat, and improves lean body mass and bone mineral density $(p=0.02)$ Decreased likelihood of total body mass loss at 6 months $(\mathrm{OR}=0.5 ; 95 \% \mathrm{Cl}=$ $0.25-0.75)$ No difference in mortality $(p=0.72)$

Propranolol at dose of $1 \mathrm{mg} / \mathrm{kg} /$ day reduces $\mathrm{HR} 15 \%$ with respect to basal The dose must increase to $4 \mathrm{mg} / \mathrm{kg} /$ day the first 10 days in order to maintain the effect $(p<0.05)$

In multivariate analyses, prehospital $\beta B$ use was associated with significant decrease in fatal outcome and healing time (5 vs $13 \%$ control; $p<0.05$ )

Decreased healing time $(16.13 \pm$ 7.40 days vs. $21.52 \pm 7.94$ days; $p=0.004)$ Less time required before skin grafting procedure ( $28.23 \pm 8.43$ days vs. $33.46 \pm$ 9.17 days; $p=0.007$ ) Decreased size of burn wound that needed grafting $(p=0.006)$ Shorter hospital LOS $(30.95 \pm 8.44$ days vs. $24.41 \pm 8.11$ days; $p=0.05$ )

Lower daily average HR over 30 days $(p<0.05)$ Decreased blood loss during grafting procedures (5-7\% improvement in perioperative hematocrit; $p=$ 0.002) Decreased time between grafting procedures (10 \pm 5 days vs. $17 \pm 12$ days; $p=0.02$ )

Less muscle wasting (mean midarm circumference $27.57 \pm$ $1.62 \mathrm{~cm}$ vs. $24.46 \pm 1.77 \mathrm{~cm} ; p<$ $0.0001)$ Faster wound healing (13.20 \pm 1.90 days vs $20.34 \pm$ 2.32 days; $p<0.001$ ) Less time required before skin grafting procedure $(23.87 \pm 2.36$ vs. $33.64 \pm 3.15$ days; $p<0.001$ ) Shorter hospital LOS $(26.69 \pm$ 3.58 days vs $37.71 \pm 3.68$ days; $p<0.001)$

\section{Traumatic Brain Injury (TBI)}

\begin{tabular}{|c|c|c|c|c|}
\hline Study & Population & Beta-blockade & Initiation & Outcome \\
\hline $\begin{array}{l}\text { Cruickshank et al. } \\
\text { (1987) RCT }\end{array}$ & $\begin{array}{l}114 \text { patients with acute head } \\
\text { injury }\end{array}$ & $\begin{array}{l}\text { Atenolol } 10 \mathrm{mg} \text { IV Q } 6 \mathrm{~h} \text { for } 3 \text { days } \\
\text { followed by atenolol } 100 \mathrm{mg} \text { PO } \\
\text { once daily for } 4 \text { days }(n=56) \text { vs } \\
\text { control }(n=58)\end{array}$ & $\begin{array}{l}\text { Immediately after hemodynamic } \\
\text { stabilization (mean } 20.2 \mathrm{~h} \text { after } \\
\text { trauma) }\end{array}$ & $\begin{array}{l}\text { Significantly inhibited the rise in } \\
\text { arterial CKMB }(p<0.01) \text { Abolished } \\
\text { focal myocardial necrotic lesions } \\
\text { Reduced likelihood of SVT and ST- } \\
\text { segment and T-wave changes }\end{array}$ \\
\hline
\end{tabular}

(Continued on following page) 
TABLE 1 | (Continued) Dosing and timing of $\beta$ B in critical illness.

\begin{tabular}{llll}
\hline Sepsis & Population & $\beta$-Blockade & Initiation \\
\hline
\end{tabular}

Study

Arbabi et al. (2007) 4,117 trauma patients with and $\quad \beta B$ therapy $(n=303)$ vs. control $(n=$ Retrospective

without head injury 3,814)

Administration of scheduled $\beta B$

during the hospital stay
Cotton et al. (2007) 420 patients with a head

Retrospective

Abbreviated Injury Scale $\geq 3$

Inaba et al. (2008)

Retrospective
1,156 patients with blunt head injuries requiring $\mathrm{ICU}$ admission
Metoprolol, propranolol, labetalol, atenolol, esmolol, or sotalol use ( $n=174)$ vs. control $(n=246)$

$\beta B$ therapy $(n=203)$ vs control ( $n=953$ )
Administration of $\beta \mathrm{B}$ for at least 2 consecutive days during hospitalization

Administration of $\beta \mathrm{B}$ during hospitalization in the ICU
Significantly decreased risk of mortality in all patients $(O R=0.3$; $p<0.001$ ) and patients with severe head injury $(\mathrm{OR}=0.2 ; p<0.001)$ No significant difference in late deaths after $48 \mathrm{~h}$ of hospitalization $(\mathrm{OR}=0.7 ; p=0.2)$

Significantly decreased mortality rate $(p=0.036)$

Significantly decreased overall mortality rate (adjusted $\mathrm{OR}=0.54$; $95 \% \mathrm{Cl}=0.33-0.91 ; p=0.01$ ) Significantly decreased mortality rate in patients $\geq 55$ years old with severe head injuries (28 vs. 60\%; $\mathrm{OR}=0.3 ; 96 \% \mathrm{Cl}=0.1-0.6$; $p=0.001$ )

\begin{tabular}{|c|c|c|}
\hline $\begin{array}{l}\text { Schroeppel et al. } \\
\text { (2010) Retrospective }\end{array}$ & 2,601 patients with blunt TBls & $\begin{array}{l}\text { Atenolol, carvedilol, esmolol, } \\
\text { labetalol, metoprolol, nadolol, } \\
\text { propranolol, or sotalol use }(n=506) \\
\text { vs. control }(n=2,095)\end{array}$ \\
\hline $\begin{array}{l}\text { Schroeppel et al. } \\
\text { (2014) Retrospective }\end{array}$ & 1,755 patients with TBls & $\begin{array}{l}\text { Atenolol, carvedilol, esmolol, } \\
\text { labetalol, metoprolol, propranolol, } \\
\text { or sotalol }(n=427) \text { vs. control }(n= \\
1,328) \text { Propranolol }(n=78) \text { vs. } \\
\text { other } \beta B(n=349)\end{array}$ \\
\hline
\end{tabular}

Administration of more than one

Decreased mortality rate $(\mathrm{OR}=$ dose of a $\beta \mathrm{B}$ during hospitalization $\quad 0.347 ; \mathrm{Cl}=0.246-0.490$; $p<0.0001)$

Administration of more than one dose of a $\beta \mathrm{B}$ during hospitalization

No difference in mortality rate between $\beta \mathrm{B}$ and control with the adjusted analysis (adjusted OR = $0.850 ; 95 \% \mathrm{Cl}=0.536-1.348)$ Decreased mortality rate with propranolol compared to other $\beta \mathrm{B}$ (3 vs 15\%; $p=0.002$ )

\begin{tabular}{cl}
$\begin{array}{c}\text { Zangbar et al. } \\
\text { (2016) Retrospective }\end{array}$ & $\begin{array}{l}356 \text { patients with blunt TBls } \\
\text { requiring ICU admission }\end{array}$ \\
\hline $\begin{array}{c}\text { Mohseni et al. } \\
\text { (2015) Retrospective }\end{array}$ & $\begin{array}{l}874 \text { patients with an isolated } \\
\text { severe TBl and an intracranial } \\
\text { injury with Abbreviated Injury } \\
\text { Scale } \geq 3\end{array}$
\end{tabular}

Metoprolol $(n=178)$ vs. no $\beta B$ ( $n$ =178)

Labetalol, metoprolol, or other $\beta \mathrm{B}$ ( $n=287)$ vs. control $(n=587)$

\section{Administration of a $\beta \mathrm{B}$ during} hospitalization with median time to first admission of 1 day and $75 \%$ of patients receiving the first dose by day 3 of a metoprolol during of a metoprolol during

Significantly decreased mortality rate (78 vs $68 \% ; p=0.04$ ) No difference in the mean heart rate ( $p=0.99)$

Significantly decreased mortality rate (11 vs $17 \% ; p=0.007$ ) Significantly increased mortality rate in patients not on prehospitalization $\beta \mathrm{B}$ (adjusted $\mathrm{OR}=$ $3.0 ; 95 \% \mathrm{Cl}=1.2-7.1 ; p=0.015)$ transferred to the floor $(n=109)$ vs. control $(n=331)$

\begin{tabular}{ll}
\hline $\begin{array}{c}\text { Ko et al. (2016) } \\
\text { Retrospective }\end{array}$ & $\begin{array}{l}440 \text { patients with a moderate to } \\
\text { severe TBI (head Abbreviated } \\
\text { Injury Scale 3-5) requiring ICU } \\
\text { admission }\end{array}$ \\
\hline $\begin{array}{c}\text { Murry et al. (2016) } \\
\text { Retrospective }\end{array}$ & $\begin{array}{l}38 \text { patients with moderate to } \\
\text { severe TBI requiring ICU } \\
\text { admission }\end{array}$
\end{tabular}

Early low dose propranolol $1 \mathrm{mg}$ IV Q $6 \mathrm{H}(\mathrm{n}=28)$ vs. standard of care, which could include $\beta \mathrm{B}$ (labetalol, metoprolol) at any point during hospitalization $(\mathrm{n}=10)$
Significantly decreased mortality rate after predictors of mortality were adjusted (adjusted OR =

$0.25 ; p=0.012)$

Administration of propranolol within $24 \mathrm{~h}$ of admission

Decreased rates of bradycardia events (1.6 vs. $5.8 ; p=0.05$ ) Decreased rates of hypotensive events (0.8 vs. $0.5 ; p=0.6$ ) Decreased ICU LOS (15.4 vs. 30.4 days; $p=0.02$ ) and hospital LOS (10 vs. 19.1 days; $p=0.05$ ) Similar mortality rates (10 vs. $10.7 \% ; p=0.9$ )

(Continued on following page) 
TABLE 1 | (Continued) Dosing and timing of $\beta B$ in critical illness.

\begin{tabular}{|c|c|c|c|c|}
\hline Sepsis & Population & $\beta$-Blockade & Initiation & Outcome \\
\hline \multicolumn{5}{|l|}{ Study } \\
\hline $\begin{array}{l}\text { Ley et al. (2018) } \\
\text { Prospective }\end{array}$ & $\begin{array}{l}2,252 \text { patients with } \mathrm{TBI} \\
\text { requiring } \mathrm{ICU} \text { admission }\end{array}$ & $\begin{array}{l}\text { Atenolol, esmolol, propranolol, } \\
\text { metoprolol, labetalol, or another } \beta B \\
(n=1,120) \text { vs. control }(n=1,132)\end{array}$ & $\begin{array}{l}\text { Administration of } \beta \mathrm{B} \text { during } \\
\text { hospitalization }\end{array}$ & $\begin{array}{l}\text { Decreased } 30 \text {-days mortality rate } \\
\text { (13.8 vs } 17.7 \% ; p=0.013) \\
\text { Decreased } 30 \text {-days mortality rates } \\
\text { with propranolol vs. other } \beta \mathrm{B}(9.3 \\
\text { vs. } 15.9 \% ; p=0.003 \text { ) Increased } \\
\text { hospital LOS }(21 \pm 25 \text { days vs } 10 \pm \\
37 \text { days; } p<0.01) \text { Increased } \\
\text { hospital LOS with propranolol vs. } \\
\text { other } \beta \mathrm{B}(21 \pm 25 \text { days vs. } 13 \pm \\
14 \text { days; } p<0.01)\end{array}$ \\
\hline
\end{tabular}

\section{Cardiac Arrest}

\section{Study}

Lee et al. (2016) Retrospective
Population

41 patients with RVF in out-ofhospital cardiac arrest
Beta-blockade

Esmolol (loading dose: 500 rg/kg, infu- sion: 0-100 $\mu \mathrm{g} / \mathrm{kg} / \mathrm{min})$ ( $n=16)$ vs control $(n=25)$
Initiation

Given after obtaining verbal informed consent from patient's proxies, written consent afterwards

\section{Outcome}

Significantly more sustained ROSC (56 vs 16\%; $p=0.007$ ) Increased survival and good neurological outcomes at 30 days, 2 months, and 6 months (18.8 vs. $8 \% ; p=0.36$ )
Driver et al. (2014) 25 patients with RVF in out-ofRetrospective
Approximately 46 min into cardiac arrest (range 34-59 min)
Higher rates of temporary (67 vs. $42 \%$ ) and sustained ROSC (67 vs
Esmolol (loading dose: $500 \mu \mathrm{g} / \mathrm{kg}$, infu- sion: $0-100 \mu \mathrm{g} / \mathrm{kg} / \mathrm{min})(\mathrm{n}=6)$ vs control $(n=19)$ $32 \%)$ Increased survival to ICU admission (66 vs. 32\%) and discharge (50 vs. 16\%) Increased discharge with favorable neurologic outcome (50 vs. 11\%) No stats are significant given small sample size

Nademanee et al (2000) Prospective
49 patients with frequent VFNT episodes with recent MI
Propranolol IV 0.15-mg/kg dose over $10 \mathrm{~min}$ and then as a 3-5-mg dose $Q 6$ h $(n=14)$ vs Esmolol IV 300-500-mg/kg loading dose for $1 \mathrm{~min}$ followed by maintenance dose of $25-50 \mathrm{mg} / \mathrm{kg} / \mathrm{min}(\mathrm{n}=7)$ vs LSGB ( $n=6)$ vs. antiarrhythmic $(n=22)$

Chatzidou et al. (2018) Prospective
60 ICD patients with recurrent VFNT within a $24-h$ period

Propranolol $40 \mathrm{mg}$ PO Q $6 \mathrm{~h}$
(cumulative dose $160 \mathrm{mg} / 24 \mathrm{~h}$ ) (n = 30) vs Metoprolol $50 \mathrm{mg} \mathrm{PO} \mathrm{Q}$ $6 \mathrm{~h}$ (cumulative dose $200 \mathrm{mg} / 24 \mathrm{~h}$ ) $(\mathrm{n}=30)$
Received sympathetic blockade treatment within $1 \mathrm{~h}$ after all of the antiarrhythmic medications initiated during the code were discontinued

Decreased mortality significantly at 1 -week (22 vs. $82 \% ; p<0.0001$ ) and 1 year ( 67 vs. $5 \% ; p<0.0001$ ) compared to antiarrhythmic medication

Propranolol patients had decreased incidence of VTNF ( $p=$ 0.001) and decreased ICD discharges $(p=0.004)$ More propranolol patients were free of arrhythmic events within $24 \mathrm{~h}$ (90 vs $53.3 \% ; p=0.03$ ) Arrhythmic events were more likely to be terminated with propranolol (hazard ratio $=0.225 ; 95 \% \mathrm{Cl}=$ 0.112-0.453; $p<0.001)$ Time to arrhythmia termination and hospital LOS were significantly shorter with propranolol compared to metoprolol ( $p<0.05$ for both)

Increased survival in multiple regression model (44 vs 79\%; $p=$ 0.005)

\section{Skrifvars et al. (2003) Retrospective}

98 patients receiving postresuscitation care within $72 \mathrm{~h}$ of out-of-hospital VF arrest (79 $\beta \mathrm{B}$ vs 19 control)
Metoprolol (at least $50 \mathrm{mg}$ PO BID Initiated within $72 \mathrm{~h}$ postresuscitation or $5 \mathrm{mg}$ IV BID) or bisoprolol (at

least $2.5 \mathrm{mg}$ two times a day orally) $\mathrm{n}$ breakdown not reported 
TABLE 1 | (Continued) Dosing and timing of $\beta$ B in critical illness.

\begin{tabular}{|c|c|c|c|c|}
\hline Sepsis & Population & $\beta$-Blockade & Initiation & Outcome \\
\hline \multicolumn{5}{|l|}{ Study } \\
\hline \multicolumn{5}{|l|}{ KEY } \\
\hline $\begin{array}{l}\text { APACHE II = acute } \\
\text { physiology and } \\
\text { chronic health } \\
\text { evaluation }\end{array}$ & $\beta \mathrm{B}=$ beta-blockers & BID = twice daily & $\mathrm{BP}=$ blood pressure & \\
\hline $\begin{array}{l}\text { CCB = calcium } \\
\text { channel blocker }\end{array}$ & $\begin{array}{l}\mathrm{Cl}=\text { cardiac index, confidence } \\
\text { interval }\end{array}$ & $\begin{array}{l}\mathrm{CKMB}=\text { myocardial isoenzyme of } \\
\text { creatine kinase }\end{array}$ & $\mathrm{CO}=$ cardiac output & \\
\hline $\begin{array}{l}\text { CVP = central } \\
\text { venous pressure }\end{array}$ & $\begin{array}{l}\text { DO2NO2 = systemic oxygen } \\
\text { delivery/consumption }\end{array}$ & $\mathrm{Ea}=$ static arterial elastance & $E F=$ ejection fraction & \\
\hline $\mathrm{HR}=$ heart rate & $\begin{array}{l}\text { ICD = implantable cardioverter } \\
\text { defibrillator }\end{array}$ & $\mathrm{ICU}=$ Intensive Care Unit & $\mathrm{IV}=$ intravenous & \\
\hline LOS = length of stay & $\begin{array}{l}\text { LSGB = left stellate ganglionic } \\
\text { blockade }\end{array}$ & MAP = mean arterial pressure & $\mathrm{Ml}=$ myocardial infarction & \\
\hline $\mathrm{N} / \mathrm{A}=$ not applicable & NGT = nasogastric tube & $\mathrm{NE}=$ norepinephrine & OER $=$ oxygen extraction ratio & \\
\hline $\mathrm{OR}=$ odds ratio & $\begin{array}{l}\mathrm{PaO} 2 \text { = arterial oxygen } \\
\text { pressure }\end{array}$ & $\mathrm{PO}=$ oral & REE $=$ resting energy expenditure & \\
\hline $\begin{array}{l}\text { ROSC = return of } \\
\text { spontaneous } \\
\text { circulation }\end{array}$ & $\mathrm{RPP}=$ rate pressure product & $\begin{array}{l}\mathrm{R} / \mathrm{VF}=\text { refractory ventricular } \\
\text { fibrillation }\end{array}$ & SBP = systolic blood pressure & \\
\hline $\begin{array}{l}\text { ScVO2 = central } \\
\text { venous oxygen } \\
\text { saturation }\end{array}$ & $\begin{array}{l}\text { SOFA = sequential organ failure } \\
\text { assessment }\end{array}$ & $\mathrm{SV}=$ stroke volume & SVI = stroke volume index & \\
\hline $\begin{array}{l}\text { SVR = systemic } \\
\text { vascular resistance } \\
\text { VT = ventricular } \\
\text { tachycardia }\end{array}$ & $\begin{array}{l}\text { SVRI = systemic vascular } \\
\text { resistance index }\end{array}$ & SVT = supraventricular tachycardia & TBSA = total body surface area & \\
\hline
\end{tabular}

\section{METHODS}

A literature search was performed to identify studies including critically ill patients who received $\beta \mathrm{B}$ therapy. The PubMed database was searched for studies published between January 1970 and March 2021 using combinations of the search terms betablockers, cardiac arrest, critical illness, esmolol, intensive care unit, sepsis, septic shock, severe burns, and traumatic brain injury. Studies reporting on patients managed in the intensive care unit (ICU) setting treated with $\beta \mathrm{B}$ were included. No limits on study designs were made and included prospective, retrospective, observational, or interventional designs. References within original research articles, review articles, editorials, abstracts, meta-analyses, and systematic reviews were screened for inclusion. A summary of the included works outlining sample size, disease state, $\beta B$ agent used, dosing, timing of initiation, and outcomes can be found in Table 1 . Furthermore, a summary of frequently questions regarding $\beta B$ in critical illness are summarized in Table 2.

\section{Beta-Adrenergic Physiology and Rationale in Critical Illness}

To appreciate the potential benefits of $\beta \mathrm{B}$ as a pharmacologicallyy supported intervention inhas several rationales for use during critical illness, conceptualization of $\beta$-adrenergic physiology during critical illness is necessary. Alterations in both as the dysregulated signaling molecules and receptorsadrenergic cascade provides intervenable pathways. Complexity further increases as the detrimental adrenergic susceptibilities differ among organ systems, withThese $\beta$-adrenergic effects in are pronounced in cardiac and pulmonary tissues most relevant to critically ill patientsduring a critically ill state (Dunser and Hasibeder, 2009). Figure 1 provides a visual representation ofillustrates the physiologic response to $\beta$ receptor agonism and antagonism, emphasizing the negative effects of $\beta$ receptor stimulation in critical illness.

\section{Catecholamine Up-Regulation}

The principle sSympathetic nervous system (SNS) signaling hormones include the catecholamines norepinephrine, (agonist of $\alpha 1, \alpha 2, \beta 1$, and minorly $\beta 2$ ), epinephrine (agonist of $\alpha 1, \alpha 2, \beta 1$, and $\beta 2$ ), and dopamine, which increase during any state of stress (dose-dependent agonist of $\alpha 1, \alpha 2, \beta 1$, and minorly $\beta 2$ ) (Table 3 ). (Dunser and Hasibeder, 2009) The stress of Ccritical illness results in massive SNS signaling (Dunser and Hasibeder, 2009). Cardiac arrest and septic shock display profound increases in circulating epinephrine (up to 300 times baseline) and norepinephrine (14 times baseline) (Wortsman et al., 1984; Jones and Romano, 1989). High These higher circulating catecholamine levels are associated with increased mortality. 
TABLE 2 | Practical questions regarding $\beta$ B use in critical illness.

1. Are $\beta$ B safe in critical illness? Yes, $\beta B$ appear to be safe in the setting of critical illness. Adequate volume resuscitation should be a target prior to $\beta B$ initiation to ensure appropriate preload

2. What are the hemodynamic effects of $\beta B$ in critical illness?

a. HR: reduce heart rate

b. SV: decreased inotropy is expected; however, in a patient with adequate preload, increased diastolic times may improve filling and improve SV

c. CO: decreased inotropy and chronotropy are expected effects; however, due to potential increases in SV/cardiac efficiency, $\beta B$ effect on CO can be neutral to improved

d. MAP: Blood pressure is the product of $\mathrm{CO}$ and systemic vascular resistance (SVR). $\beta \mathrm{B}$ have no notable effects on SVR, but potential improvements in CO can be observed, especially in the setting of mitigating arrhythmias (e.g., atrial fibrillation). As such, cardioselective $\beta B$ use may be associated with neutral to positive effects on MAP. 3. How does $\beta B$ use effect vasoactive agents like norepinephrine?

When used at the appropriate time (i.e. if persistent tachycardia remains despite fluid resuscitation and control of pain and agitation), $\beta \mathrm{B}$ can be norepinephrine-sparing allowing for decreases in norepinephrine dosages without a higher need for inotropic support. $\beta \mathrm{B}$ allow decreased $\mathrm{HR}$ which facilitates increased ventricular filling times during diastole, subsequently increasing SV, SVR, and left ventricularLV stroke work to maintain MAP and lower catecholamine requirements

4. Should pulmonary conditions like COPD or asthma preclude $\boldsymbol{\beta} \mathbf{B}$ use in critically ill patients? In the setting of a compelling indication (e.g., atrial fibrillation), no, $\beta B$ should not be withheld due to this co-morbidity. Further, continuation of home $\beta$ B use even in the setting of pulmonary conditions appears safe and associated with improved outcomes. In particular, cardioselective $\beta B$ (e.g., esmolol) appear to be the lowest risk

5. How should $\beta B$ be dosed in different types of critical illness?

a. Sepsis: Data are mixed; however, esmolol $0.5 \mathrm{mg} / \mathrm{kg} / \mathrm{min}$ or $25 \mathrm{mg} / \mathrm{h} \mathrm{IV}$ continuous infusions are the two most frequent published approaches. In most studies, infusions were titrated to achieve a $20 \% \mathrm{HR}$ reduction

b. Burns: Dosing ranges of propranolol $0.5-3 \mathrm{mg} / \mathrm{kg} /$ day IV or PO divided three to four times per day were most prevalent in the existing literature

c. TBI: A wide variety of agents and doses have been studied with most robust data reporting use of atenolol, esmolol, propranolol, metoprolol, or labetalol, but failing to mention dosing strategies

d. Cardiac Arrest: IV esmolol loading doses were reported as 300-500 $\mu \mathrm{g} / \mathrm{kg}$ as well as 300-500 mg/kg. Propranolol, metoprolol, and bisoprolol were also utilized

and may potentially be used as an additional factor in predicting mortality These higher circulating catecholamines can predict mortality in the critically ill (Benedict and Rose, 1992; Boldt et al., 1995), but wWhether catecholamine upregulation represents treatable pathophysiology or a necessary compensation inevitably linked to disease severity and poorer outcomes remains debatedshould be targeted remains unclear, as it provides the physiologic adaptation to shock and critically ill states.

\section{Cardiac $\beta$ Effects}

$\beta$-adrenergic pathways extensively regulate cardiac function and function and, specifically, hemodynamics due to extensive cardiac expression. $\beta 1$ comprises $80 \%$ of cardiac $\beta$-receptors and mediates inotropy, chronotropy, lusitropy (i.e. relaxation rate), and dromotropy (i.e. conduction speed). However, at high concentrations of catecholamines, the lusitropic effect is overwhelmed by tachycardia and increased contractility (Dunser and Hasibeder, 2009; Wachter and Gilbert, 2012). $\beta 2$ produces similar cardiac effects to $\beta 1$ (Belletti et al., 2020), but sustained $\beta 2$ activation leads to a counteracting of $\beta 1$ effects (Lucia et al., 2018). Moreover, the cardiac-mediated epinephrine response appears independent of functional $\beta 2$ and is mediated primarily by $\beta 1$ relies on $\beta 1$ activation (Chruscinski et al., 1999). This Experimental evidence touts $\beta 1$ activation appearspathways as proapoptotic to cardiac myocytes, while $\beta 2$ may confer protection (Patterson et al., 2004). Although, interestingly, recent preclinical data in mice demonstrated prevention of cardiac mitochondrial dysfunction via ablation of $\beta 2$ signaling after burns (El Ayadi et al., 2019). $\beta 1$ predominates cardiac expression over $\beta 2$ (4 to 1 ), but states such as HF can tip the balance nearly even through $\beta 1$ downregulation by sustained adrenergic stimulation (Bristow et al., 1986). Increased $\beta 2$ expression may provide benefits through increase contractility and angiogenesis, Research diverges in identifying cardioprotective vs. deleterious roles from the higher proportion of $\beta 2$ expression as some reports indicate improvements in contractility, angiogenesis, and cardiac remodeling (Rengo et al., 2012). but In contrast, others implicatemay promote $\beta 2$ as arrhythmiasmogenic (Nguyen et al., 2015). However, commonly used transgenic mice strains overexpressing $\beta 2$-receptors may represent non-physiologic environments given that HF does not upregulate $\beta 2$-receptors. This augmented receptor physiology may increase the rate of arrhythmogenicity attributed to $\beta 2$-receptors in these animal studies (Bristow et al., 1986). Unlike $\beta 1$ and $\beta 2, \beta 3$ induces negative inotropy and blunts the catecholamine response (Moniotte et al., 2001), and expression is upregulated in critical illness (Moniotte et al., 2007). IThe increased $\beta 3$ expression may prime the heart for consequences like septic myocardial depression (Yang et al., 2018). Interestingly, Myagmar et al. recently described the absence of $\beta 2$ and $\beta 3$ in cardiac myocytes, while $\beta 1$ was present in all myocytes. $\beta 2$ and $\beta 3$ are primarily in other cell types (e.g., endothelial cells) underscoring the reliance on $\beta 1$ in cardiac muscle, which raise further concerns regarding the appropriateness of artificial $\beta 2$ overexpression in cardiac myocytes (Myagmar et al., 2017).

Clinical evidence supporting harmful $\beta$-mediated harmful effects has been reported. $\beta 1$ drives Ttachycardia in critical illness (primarily $\beta 1$ driven) may increase the, increasing the risk of cardiac events in those with pre-existing heart disease (Sander et al., 2005). Additionally, left ventricular (LV) apical ballooning syndrome (i.e., Takotsubo syndrome) has a links to endogenous adrenergic stimulation (Wittstein et al., 2005) and specifically $\beta$-agonism (Hajsadeghi et al., 2018). In sepsis, despite elevated catecholamines, overall $\beta$-receptor downregulation contributes to septic myocardial dysfunction (Suzuki et al., 2017). Cumulatively, these cardiac effects support the rationale 


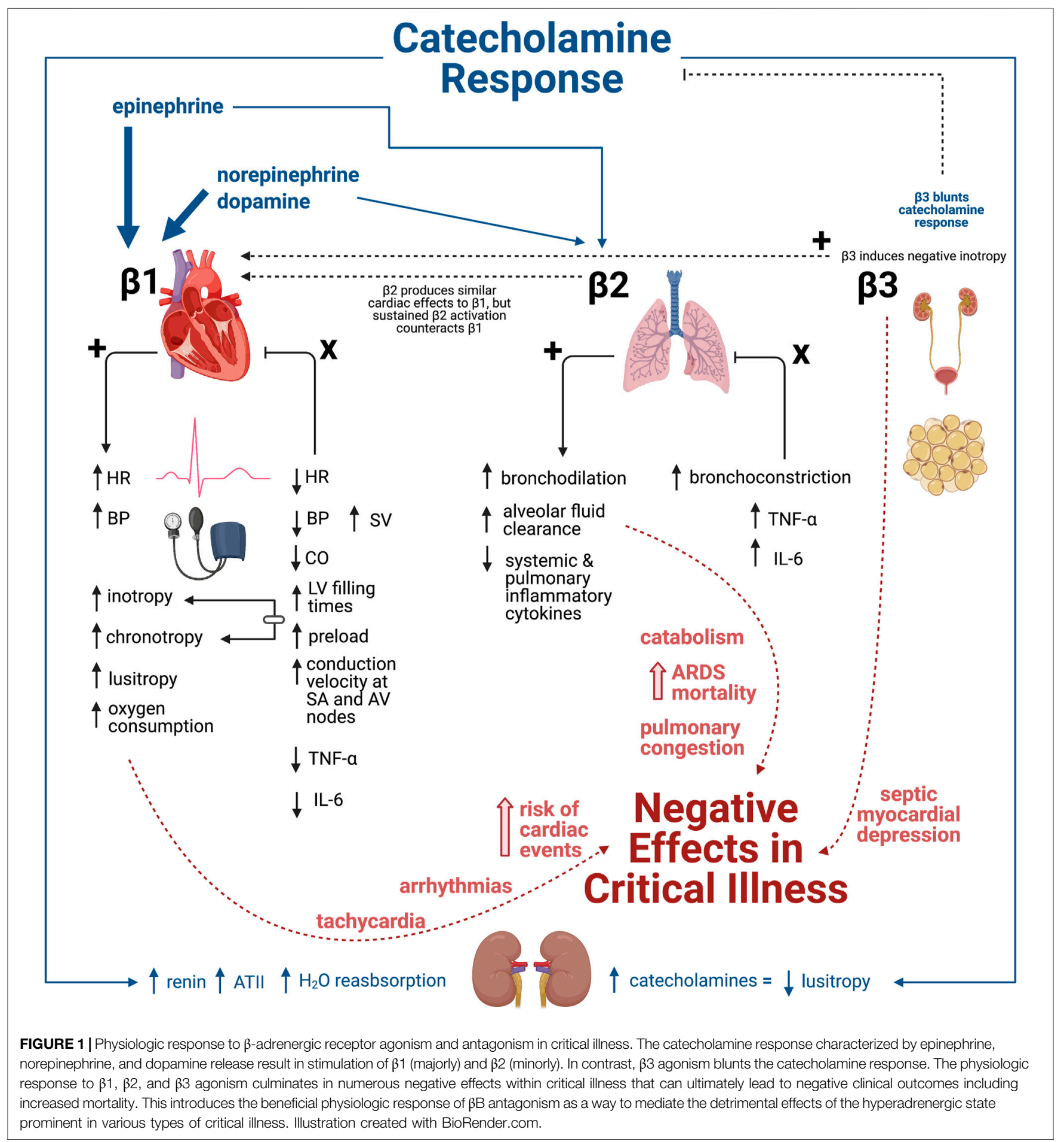

of study behindfor $\beta 1$-selective $\beta B$ (e.g., esmolol) in critical illness, as $\beta 2$ and $\beta 3$ are is potentially protective.

\section{Cardiac $\beta$-Blockade Effects}

Antagonism The antagonism of cardiac $\beta$-receptors produces negative inotropic and chronotropic effects asslows conduction velocity through sino-atrial and atrioventricular nodes and produces negative inotropic and chronotropic effects decreases. These effectsThis mechanism may decrease cardiac output and blood pressure, demonstrated by. Experimental studies have shown impairment ined right ventricular function and worsened perfusion with $\beta B$ when useduse at the onset of septic shock (Coppola et al., 2015). Typically, these effects limit their use in critical illness application; h. However, 
TABLE 3 | Adrenergic receptor selectivity of endogenous catecholamines.

\begin{tabular}{lcccccc}
\hline Catecholamine & $\boldsymbol{\alpha 1}$ & $\boldsymbol{\alpha 2}$ & $\boldsymbol{\beta 1}$ & $\boldsymbol{\beta 2}$ & DA1 & DA2 \\
\hline Epinephrine & +++ & +++ & +++ & +++ & - & - \\
Norepinephrine & +++ & +++ & ++ & + & - & - \\
Dopamine 0-3 $\mu \mathrm{g} / \mathrm{kg} / \mathrm{min}$ & - & + & - & - & +++ & ++ \\
$2-10 \mu \mathrm{g} / \mathrm{kg} / \mathrm{min}$ & + & + & ++ & + & ++ & ++ \\
$>10 \mu \mathrm{g} / \mathrm{kg} / \mathrm{min}$ & ++ & ++ & ++ & + & ++ & ++ \\
\hline
\end{tabular}

$D A=$ dopaminergic receptor.

Adapted from Table 2 in Dunser et al. (Dunser and Hasibeder, 2009)

experimental assessments are often limited by short observation times (several hours) compared to more extended follow-up in clinical studies that would evaluate judicious use of $\beta \mathrm{B}$ after acute hemodynamic stabilization. Preclinical studies have suggested positive effects as beta-blockade with agents selective for $\beta 1$ agents may reduced tumor necrosis factor alpha (TNF- $\alpha$ ) and interleukin 6 (IL-6) in the serum and myocardiumsystemic and cardiac inflammation (Suzuki et al., 2005; Hagiwara et al., 2009). HoweverIn contrast, antagonism of $\beta 2$ increases TNF- $\alpha$ and IL6inflammation and may exacerbate the physiologic changes seen inof sepsis (Lang et al., 2008), further supporting $\beta 1$ selective benefits.

The hemodynamic benefits of $\beta \mathrm{B}$ may improve cardiac function in critical illness through may occur through increased left ventricula LVr filling times by reducing heart rateas heart rate (HR) lowers and there is enhanced ventricular-arterial (V-A) coupling (Mathieu et al., 2016). Patients with septic shock experience a V-A decoupling associated with poor LV function (Guarracino et al., 2014). Morelli et al. demonstrated $\beta 1$ selective esmolol reduced arterial elastance, and increased stroke volume, reduced with esmolol (a $\beta 1$ selective $\beta B$ ) heart rate in septic shock reduction, suggesting improved V-A coupling (Morelli et al., 2016). Further, esmolol increased stroke volume (SV) in septic shock despite decreases in cardiac output (CO). Figure 2 describes the hemodynamic effects of sepsis and concomitant $\beta \mathrm{B}$. $\beta \mathrm{BThese}$ effects are attributable to the reductions in heart rateHR reductions, enhancing end-diastolic filling of the left ventricleLV and thus increasingto increase preload. No differences in oxygenation and tissue perfusion were noted despite decreased CO (Du et al., 2016). Experimentally, esmolol protects myocardial function in sepsis, likely through mitigating apoptotic pathways in the myocardium that are associated with elevated $\beta 1$ stimulation (Herndon et al., 2001; Wang et al., 2017). Indeed, esmolol added to cardioplegic solutions for cardiac surgery reduced post-surgery troponins suggesting cardiac tissue preservation (Bignami et al., 2017). In acute decompensated HF, continuation of chronic $\beta \mathrm{B}$ appears to prevent death (Prins et al., 2015; Jones et al., 2020). While it may seem logical to stop negative inotropes in patients hospitalized with a failing heart, discontinuation of $\beta B$ did not significantly affect hemodynamics in these patients (Butler et al., 2006). A meta-analysis of $\beta B$ effects in septic shock trials supports neutral hemodynamic effects after initial resuscitation despite vasopressor support requirements after initial resuscitation (Lee et al., 2019). Taken together, these The extrapolation of

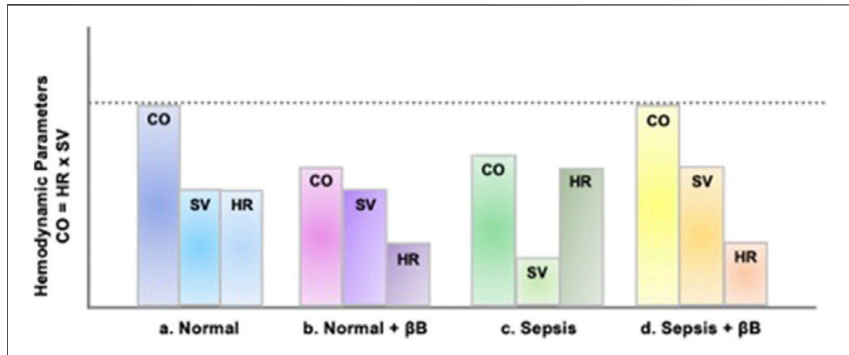

FIGURE 2 | Hemodynamic effects of sepsis and $\beta$-Blockade. In panel A, the stroke volume (SV) and cardiac output (CO), stroke volume (SV), and heart rate $(\mathrm{HR})$ of a normal, healthy individual are presented. In panel $\mathrm{B}$, due to the negative inotropy associated with $\beta B$, which causes reduced $H R$, the overall $\mathrm{CO}$ is reduced despite normal SV. In panel $\mathrm{C}$, sepsis results in tachycardia, due to excessive sympathetic activation. This increase in HR does not allow for adequate ventricular filling causing a decrease in CO secondary to a decrease in SV. In panel D, given that venous return (i.e., preload) is adequate, then $\beta \mathrm{B}$-induced $\mathrm{HR}$ reduction allows for more left ventricular filling time, subsequently decreasing afterload and increasing SV enough to overcome decreased $\mathrm{HR}$ and improved $\mathrm{CO}$.

preclinicalpreclinical and clinical data support beneficial, or at least safe, cardiac and hemodynamic effects cardiac $\beta \mathrm{B}$ during critical illness data. to clinical settings support beneficial effects, although clinical studies lack details discerning if these suggested mechanisms are the drivers of clinical benefit.

\section{Pulmonary $\beta$ Effects}

The pulmonary vasculature has modest concentrations of $\beta$-receptors. Within the lungs, $\beta 2$-receptors are the most consequential in the lungs as they outnumber $\beta 1$ three to one in most pulmonary tissues and are the exclusive $\beta$-receptor present on pulmonary vascular smooth muscle (Carstairs et al., 1985). $\beta 2$-receptors in the epithelium contribute to alveolar fluid clearance, while those in smooth muscle promote bronchodilation (Mutlu and Factor, 2008). $\beta 1$ receptors present onof the alveolar wall and submucosal glands (Carstairs et al., 1985) and contributes to alveolar fluid clearance (Sakuma et al., 2001), although not to the extent of $\beta 2$ (Mutlu et al., 2004).

Adrenergic overstimulation has several pulmonary effects germane to critical illness concerns, including pulmonary edema and elevated pulmonary pressures with right heart dysfunction, most notably through a-receptor-mediated vasoconstriction (Dunser and Hasibeder, 2009). a-receptormediated vasoconstriction increases the displaced blood volume into the pulmonary circulation, increasing congestion and capillary wall stress. Pressure increase and fluid retention readily shift fluid into the pulmonary interstitium and the alveoli, especially when inflammation disrupts the capillary barrier. Although less influential than a stimulation, $\beta 1$ stimulation can augment right ventricular output, further increasing pulmonary blood volume and pulmonary capillary pressures (Rassler, 2012). However, $\beta 2$-agonism is often associated with improvements in mechanisms thatmay mitigate prevent edema throughsuch as alveolar fluid clearance (Maron et al., 2009). $\beta 2$ agonism may produce other protective pulmonary effects such as 
reductions in systemic and pulmonary inflammatory cytokines (Maris et al., 2005; Bosmann et al., 2012) and prevent capillary permeability (de Prost et al., 2008). Clinical trials failed to translate pre-clinical evidence into positive outcomes as $\beta 2$ agonism increased acute respiratory distress syndrome mortalitylinical trials in critical illness have failed to show positive outcomes as $\beta 2$-agonism increased mortality from acute respiratory distress syndrome (Gao Smith et al., 2012). The lack of benefit may occur secondary to dysfunctional $\beta 2$ receptors during prolonged inflammatory states (Giembycz and Newton, 2006; Belletti et al., 2020). Notably, $\beta 2$-mediated vasodilation may detrimentally affect blood shunting in cardiopulmonary resuscitation leading to the distribution of blood from well to unventilated alveoli (Thrush et al., 1997). The mode of critical illness likely influences the degree of pulmonary pathophysiology with $\beta$-receptor stimulation, with insufficient evidence to malignCurrently, insufficient evidence exists to support a role for $\beta 2$ stimulation as helpful or harmful in critical illness and possible harm in long-term pulmonary dysfunction like acute respiratory distress syndrome.

\section{Pulmonary $\beta$-Blockade Effects}

$\beta B$ provides a potential strategy to improve pulmonary adrenergic response. Prescribing of $\beta \mathrm{B}$ typically warrants caution in pulmonary pathologies, most notably chronic obstructive pulmonary disease (COPD) and asthma, as $\beta \mathrm{B}$ can reverse the benefits of $\beta 2$-mediated bronchodilation, although cardioselectivity $\beta 1$ blocking agents eliminates some concern (MacNee, 2019). Nevertheless, Aa recent large clinical trial determined metoprolol use in COPD patients without cardiac indications for a $\beta \mathrm{B}$ resulted in increased exacerbations (Dransfield et al., 2019). However, in critically ill patients with acute respiratory failure and COPD, $\beta 1$-selective $\beta B$ did not affect ICU length of stay (Kargin et al., 2014). Additionally, continuing cardioselective $\beta \mathrm{B}$ for patients with underlying cardiac indications hospitalized for COPD exacerbations appears safe (Stefan et al., 2012). In asthma, several clinical and database studies have suggested that $\beta \mathrm{B}$ use does not worsen airway hyperresponsiveness or asthma exacerbations (Short et al., 2013; Morales et al., 2017). A network meta-analysis of 24 clinical trials concluded that non-selective $\beta B$ (specifically oral timolol and propranolol infusions) were associated with a higher incidence of asthma attacks than $\beta 1$-selective $\beta \mathrm{B}$. MoreoverAdditionally, antecedent cardioselective $\beta \mathrm{B}$ therapy has been associated with lower mortality in ICU patients with acute respiratory failure, and $\beta \mathrm{B}$ withdrawal may worsen mortality (Noveanu et al., 2010). In a retrospective assessment of $\beta B$ commencement after about 7 days of ICU admission, no alterations in pulmonary function occurred (Van Herpen et al., 2019). Given the current evidence, compelling cardiac indications (e.g., atrial fibrillation, ischemic heart disease) should drive $\beta \mathrm{B}$ use in critically ill patients, and COPD and asthma should not restrict $\beta B$ use. given the current evidence.

Some preclinical evidence suggests possible protective mechanisms of $\beta \mathrm{B}$ germane to critical illness. Maccari et al. reported various selective and non-selective $\beta B$ prevented catecholamine-induced $\beta 2$ downregulation in-vitro (Maccari et al., 2020). Other pre-clinical studies demonstrate $\beta B$ lungprotective effects in sepsis-induced acute lung injury. The ultrarapid $\beta \mathrm{B}$, landiolol, suppressed lung injury and reduced lung injury associated protein, high-mobility group box 1 (HMGB1 ), in a rat lipopolysaccharide sepsis model (Hagiwara et al., 2009). The mechanism of pulmonary benefit of $\beta B$ in these settings remains a conjecture, although when applied in clinical settings, the effects do not appear detrimental to pulmonary physiology.

\section{Disease-specific Evidence for $\beta$-Blockade Sepsis}

Dysregulated inflammatory response and catecholamine upregulation affect nearly every organ system in sepsis. Two specific derangements include hemodynamic compromise and metabolic alterations, which may open a role for $\beta \mathrm{B}$ (Plank et al., 1998; O’Dwyer et al., 2006; Furian et al., 2012). Sepsis leads to elevated serum pro-inflammatory cytokines (e.g.,TNF- $\alpha$, IL-1 $\beta$, and IL-6). Cytokine up-regulation has multiple deleterious effects, possibly mitigated by $\beta$ B (Cain et al., 1999; Hsueh and Law, 2003). Indeed, $\beta B$ have been proposed to reduce sepsisinduced cardiac dysfunction, improve the sepsis-induced hypermetabolic state, and play a role in immunomodulation by preventing lymphocyte apoptosis prevalent within inflammatory mechanisms of sepsis (Suzuki et al., 2017). Additionally, sepsis precipitates tachycardia, which reduces filling time and increases the risk of arrhythmias, potentially exacerbating the poor hemodynamics of impaired systemic vascular resistance (SVR) (Jacobi, 2002; Suzuki et al., 2017). Heart rate reduction via $\beta 1$ blockade in the setting of adequate preload can decrease myocardial oxygen consumption, increase diastolic filling time, and increase coronary perfusion time, all potentially reducing the risk of myocardial ischemia and improvement in end-organ perfusion. $\beta 1$ blockade may result in hemodynamically significant hypotension in patients without adequate preload and should therefore be used cautiously or avoided. The 2016 Surviving Sepsis Guidelines do not make recommendations regarding $\beta \mathrm{B}$ continuation or initiation in septic patients (Rhodes et al., 2017).

The hemodynamic improving effects of acute $\beta B$ use in sepsis remain controversial; however, case series and small retrospective and prospective studies have established a plausible safety profile. As early as 1972, a case series in refractory septic shock patients documented the hemodynamic effects of propranolol (Berk et al., 1972). The cases conceptualized hyperdynamic vs. hypodynamic shock, given the observation that three patients dying after propranolol use had severely reduced CO compared to those who survived. Analysis of hemodynamic parameters continued in retrospective reviews of septic patients; however, unlike Berk et al., a study conducted by Schmittinger et al (Schmittinger et al., 2008) found no change in cardiac index (CI) following milrinone infusion with enteral metoprolol initiated after hemodynamic stabilization. HR control (65-95 bpm) was achieved in 39 out of 40 patients in addition to a significant increase in stroke volume index (SVI) $(p=0.002)$, and central venous pressure (CVP) along with dosages of norepinephrine, vasopressin, and milrinone all decreased $(p<0.001)$. Other small retrospective studies of $\beta \mathrm{B}$ in 
sepsis have not shown increases in mortality through acute $\beta \mathrm{B}$ use (Gutierrez et al., 2009).

Subsequent small prospective observational studies continued to analyze hemodynamic parameters following $\beta B$, specifically esmolol, in sepsis. Some studies demonstrated significantly decreased CO proportional to the decreases in HR (Gore and Wolfe, 2006) while others showed unchanged CO (Morelli et al., 2016) or insignificant reductions in CO (Balik et al., 2012). A more consistent trend was seen with regard to SV with evidence of significant (Du et al., 2016; Morelli et al., 2016) or negligible increases documented (Balik et al., 2012). In a subgroup analysis, $\mathrm{Du}$ et al. demonstrated that in patients with increased SV, esmolol therapy had a lower risk for decreased CO (Du et al., 2016). Similarly to Schmittinger et al. (Schmittinger et al., 2008), Morelli et al.(Morelli et al., 2016) observed reduced norepinephrine requirements after esmolol, although not all studies uniformly observed this difference (Balik et al., 2012). Measures of tissue perfusion, including lactate levels, were conflicting amongst studies, with some showing significant decreases in the esmolol group (Du et al., 2016) while others had more substantial reductions in the control group (Shang et al., 2016). The prospective studies did not analyze the risk or incidence of mortality associated with esmolol therapy, but Shang et al.(Shang et al., 2016) concluded a significantly shorter mechanical ventilation duration with esmolol compared to control ( $p<0.05$ ). Concerning the timing for the initiation of esmolol, these prospective studies were relatively consistent by attempting to correct preload through fluid resuscitation before administration of an esmolol loading dose. Nevertheless, timing, thresholds, and parameters for hemodynamic stabilization varied. These retrospective and prospective data are collectively limited by small sample sizes and lack relevant clinical outcomes, establishing impetus for larger randomized trials.

The seminal Morelli et al. (Morelli et al., 2013) phase 2 study of esmolol in septic shock patients requiring high-dose vasopressors revived discussion of $\beta B$ in sepsis. Esmolol achieved the target $\mathrm{HR}$ $(80-94 \mathrm{bpm})$ in all patients $(-28 \mathrm{bpm} ; \mathrm{IQR}=-37$ to -21$)$ compared to standard of care $(-6 \mathrm{bpm} ; 95 \% \mathrm{CI}=-14$ to 0$)$ and resulted in a mean reduction of $18 \mathrm{bpm}(p<0.001)$. The esmolol group exhibited improvements in SV and left ventricularLV stroke work index and decreases in norepinephrine and fluid requirements. Esmolol also improved $\mathrm{pH}$, base excess, and arterial lactate. Several other randomized controlled trials (RCTs) evaluated $\beta$ B in sepsis (Orbegozo Cortes et al., 2014; Yang et al., 2014; Wang et al., 2015; Xinqiang et al., 2015; Wang et al., 2017; Liu et al., 2019; Kakihana et al., 2020). Cumulatively, these trials have recently been assessed in systematic reviews and meta-analyses.

Chacko et al. evaluated 9 studies in a systematic review and found benefit from most studies with regards to heart rate control, decreased mortality, and acid-base parameters although strength of evidence is limited due to heterogeneity and inclusion of only one RCT (Chacko and Gopal, 2015). Sanfilippo et al. (Sanfilippo et al., 2015) was the next systematic review published that included two RCTs with the additional evidence from Yang et al. (Yang et al., 2014) At this time, the sizeable differences in sample size and trial design did not allow for a meta-analysis, but this systematic review further affirmed that $\beta B$ use in septic and septic shock patients conferred decreased HR without significant adverse effects (Sanfilippo et al., 2015). The previous systematic reviews include a range of trial designs, but a meta-analysis conducted in 2018 evaluated the use of esmolol on septic shock and sepsis from five RCTs (Liu et al., 2018). The three trials that reported survival rate showed that esmolol use when compared to control was associated with a significantly increased rate of survival $(\mathrm{RR}=2.06 ; 95 \% \mathrm{CI}=$ $1.52-2.79 ; p=0.006)$. With regard to hemodynamics, esmolol use showed no influence on MAP, CVP, or central venous oxygen saturation $\left(\mathrm{ScVO}_{2}\right)$ but did reduce $\mathrm{HR}$ and cardiac biomarker troponin I. In 2019, Lee et al. (Lee et al., 2019) published a systematic review of 14 studies which included 5 RCTs, although only three of these RCTs were the same as those included in the Liu et al. meta-analysis. Six of the studies assessed $\beta B$ use and mortality, which despite possible publication bias, demonstrated average odds ratio of $0.4072(95 \% \mathrm{CI}=0.2602-0.6373)$ in favor of $\beta B$ use.

Since the publication of these systematic reviews and metaanalyses there has been an increased focus on the treatment of tachyarrhythmias in sepsis. Initial evidence garnering support for $\beta B$ use in septic patients with atrial fibrillation resulted from a 2016 propensity-matched cohort study. This analysis concluded that $\beta \mathrm{B}$ were associated with lower hospital mortality when compared to calcium channel blockers (CCBs), digoxin, and amiodarone (Walkey et al., 2016). With regard to rate control, Bosch et al. found that in comparison to CCBs, amiodarone, and digoxin, $\beta \mathrm{B}$ improved $\mathrm{HR}$ control to $<110 \mathrm{bpm}$ at 1 hour for the treatment of sepsis-associated atrial fibrillation, although this effect did not persist to show meaningful difference at $6 \mathrm{~h}$ (Bosch et al., 2020). While these studies included a variety of $\beta B$ agents, newer evidence has shifted to solely focus on the use of ultra-short-acting $\beta \mathrm{B}$, esmolol and landiolol. Of note, landiolol is not available for use in the United States. Kakihana et al. (Kakihana et al., 2020) analyzed the safety and efficacy of landiolol in a multicenter, open-label RCT in Japan that showed significant improvements in HR control and decreased incidence of new-onset arrhythmias. This trial specifically focused on a patient population with $\mathrm{HR} \geq 100 \mathrm{bpm}$ maintained for at least $10 \mathrm{~min}$ without a change in catecholamine dose and with a diagnosis of atrial fibrillation, atrial flutter, or sinus tachycardia. The most common adverse effect was hypotension, which quickly resolved in all instances given the ultra-short-acting nature of the drug. Hasegawa et al. performed a systematic review and meta-analysis of seven RCTs associated with esmolol and landiolol use in patients with persistent tachycardia (defined as HR > $95 \mathrm{bpm}$ ) despite initial resuscitation.(Hasegawa et al., 2021). Six of the RCTs included reported 28-days mortality. The use of ultra-short-acting $\beta \mathrm{B}$ in this patient population of 572 patients was found to be associated with significantly lower 28 -days mortality $(\mathrm{RR}=0.68$; $95 \% \mathrm{CI}=$ $0.54-0.85 ; p<0.001$ ) with an absolute risk reduction of $18.2 \%$ conferring a number needed to treat of 6 to prevent one patient death.

The use of beta-blockade in septic patients remains controversial especially with regard to timing of initiation. 
Tachycardia in the early stages of un-resuscitated sepsis is a major compensatory mechanism to ensure cardiac output, oxygen delivery, and perfusion. The use of beta-blockade, specifically with esmolol and landiolol, has been shown to reduce heart rate in the septic patients without deleterious effects on end-organ perfusion and may be associated with improved survival rates. Despite some dosing and timing variation within the RCTs that have been conducted, there is a general consensus that $\beta \mathrm{B}$ should not be initiated until at least $6 \mathrm{~h}$, and in some trials $24 \mathrm{~h}$, after the initial fluid resuscitation and vasopressor use. With this in mind, $\beta B$ therapy may be initiated while patients are still requiring vasopressors. In fact, many studies described potential for decreased norepinephrine requirements with $\beta B$, instigating hypotheses of $\beta B$ as vasopressor-sparing with potential to avoid deleterious effects of prolonged, high catecholamine requirements. Therefore, use of esmolol should be based on patient specific factors and likely should be considered only after initial resuscitation and once hemodynamic stabilization with vasopressors is achieved. Without large randomized controlled trials evaluating and elucidating the optimal dosing regimen and initiation timing considerations, the cost of esmolol infusion course should be considered as many hospital formularies restrict its use due to the extensive significant cost of the drug.

There are numerous retrospective studies that have investigated premorbid $\beta \mathrm{B}$ exposure prior to admission to the ICU with a diagnosis for sepsis that have conferred mortality benefit. Macchia et al. performed a retrospective observational study in 9,465 septic patients that concluded lower 28-days mortality in patients previously prescribed $\beta \mathrm{B}$ (Macchia et al., 2012). As part of a national cohort of Medicare beneficiaries, Singer et al. determined outpatient $\beta B$ prescription was associated with a significantly reduced in-hospital and 30-days mortality, with no difference in regards to cardioselective compared to nonselective $\beta B$ (Singer et al., 2017). In contrast, a recent observational cohort study by Guz et al. found that antecedent cardioselective $\beta \mathrm{B}$ were associated with a stronger protective effect on 30-days mortality rate reduction than noncardioselective $\beta \mathrm{B}$ for patients admitted with sepsis (Guz et al., 2021). Based on additional subgroup analyses according to tachycardia stratification, both patients with absolute and relative tachycardia on presentation exhibited reduced 30 -days mortality rates with $\beta B$ use.

Beyond initiation of $\beta B$ in sepsis or premorbid $\beta B$ use, continuation of chronic $\beta B$ in patients admitted with sepsis and septic shock remains controversial, with common practice being to discontinue anti-hypertensive therapy upon admission. A prospective, observational study evaluated 296 patients admitted with severe sepsis or septic shock who were on chronic beta-blocker therapy (Fuchs et al., 2017). Chronic beta-blocker therapy was continued in 167 patients and was associated with significant decreases in hospital, 28-days, and 90-days mortality $(p<0.05)$ compared to $\beta B$ cessation. Continuation of beta-blockade therapy was also associated with decreased crystalloid requirements during the first $24 \mathrm{~h}$ ( $p=0.049$ ) without increases in need for vasopressor, inotropic support, or low-dose steroids. To build on these results, a systematic review including a total of nine studies and over 6,500 patients found that premorbid beta-blocker exposure, regardless of continuation, in patients with sepsis was associated with reduced mortality (Tan et al., 2019). Although the precise mechanism of benefit in these settings is unknown, potential explanations beyond the mechanisms mentioned previously in this section include the prevention of rebound effects of tachycardia, hypertension, and arrhythmias caused by abrupt $\beta \mathrm{B}$ withdrawal.

In summary, Tthe hemodynamic evidence for $\beta \mathrm{B}$ use in sepsis has been proven as there are numerous studies demonstrating decreased HR without significant change in MAP, CVP, or $\mathrm{ScVO}_{2}$. Further, the recent evidence for ultra-short-acting $\beta \mathrm{B}$, esmolol and landiolol, especially with regard to decreased incidence of arrhythmias and 28-days mortality benefit is clinically significant. In fact, some are realizing a need to stratify subgroups within septic cohorts based on the potential benefit of cardiovascular intervention to decrease the negative consequences of tachyarrhythmias (Morelli et al., 2020). The inconsistencies in terms of dosing and timing of initiation within the existing evidence require subsequent investigation in robust randomized controlled trials. Overall, esmolol was the most studied $\beta \mathrm{B}$ in sepsis, and initial doses varied over a wide range of either weight based dosing (most commonly $0.05 \mathrm{mg} / \mathrm{kg} / \mathrm{min}$ ) or standard dosing (most commonly $25 \mathrm{mg} /$ h) with doses titrated to heart rate reductions of $20 \%$ or a heart rate goal of 70-100 bpm. Additionally, there is ample evidence to show antecedent $\beta B$ use confers mortality benefit, but there is only one RCT evaluating the continuation of chronic $\beta B$ therapy in acute sepsis, which warrants supplementation.

\section{Burns}

Severe burns lead to catecholamine release and a hypermetabolic state characterized by increased cardiac output, increased energy requirements, muscle breakdown, and general catabolism (e.g., reduced bone density, etc) (Wilmore et al., 1974; Herndon et al., 2001). This response lasts for at least 9 months and up to 2 years and is associated with a hypercatabolic state leading to muscle and bone loss (Hart et al., 2000; Przkora et al., 2006). $\beta 1$ receptor mediated lipolysis and agonism of $\beta 2$ receptors can cause glycogenolysis and gluconeogenesis within hepatocytes due to catecholamine stimulation (Novotny et al., 2009). Hypermetabolism can negatively impact the function of skeletal muscle, skin, and the immune system, ultimately resulting in multiorgan dysfunction and even death (NúñezVillaveirán et al., 2015).

As such, $\beta B$ are an attractive intervention to prevent the hyperadrenergic cascade that follows burn injury. Preclinical animal studies examining propranolol to improve wound healing following burn injury have noted enhanced wound healing and reduced activity of local inflammatory pathways (Romana-Souza et al., 2008; Zhang et al., 2009). Nearly all studies investigating $\beta \mathrm{B}$ in burn injuries have been conducted in pediatric patients using propranolol (Núñez-Villaveirán et al., 2015). Propranolol has been associated with a decrease in HR and oxygen consumption and the reversal of catabolism, evidenced by significant reductions in resting energy expenditure (REE) and 
prevention of lean body mass loss (Herndon et al., 2001; Jeschke et al., 2007; Williams et al., 2011; Herndon et al., 2012).

Baron et al. (Baron et al., 1997) deemed propranolol use safe and effective for $\geq 10$ days following severe burns ( $\geq 40 \%$ of total body surface area [TBSA]) in 22 children aged $1-10$ years old. In this population, propranolol use demonstrated significantly decreased $\mathrm{HR}$ and rate pressure product (RPP), defined as MAP multiplied by HR, without adverse effects. Herndon et al. (Herndon et al., 2001) extended this time frame to at least 2 weeks by evaluating propranolol in 25 pediatric burn patients $(>40 \%$ of TBSA). Propranolol showed successful attenuation of the hypermetabolic response by decreasing REE, oxygen consumption, and muscle catabolism. Additionally, lean mass loss at 2 weeks was prevented by propranolol (9\% loss vs $1 \%$ loss; $p=0.003$ ). Similarly, Jeschke et al. (Jeschke et al., 2007) found improvements in REE with propranolol in 245 severely burned children. In a separate trial, Herndon et al. (Herndon et al., 2012) investigated propranolol given within $96 \mathrm{~h}$ from admission and continued for a year compared to control in 179 pediatric burn patients with burns $>30 \%$ of TBSA. While there was no significant difference in mortality $(p=0.72)$, propranolol use did result in reduced cardiac work and improved lean body mass and bone density without adverse events. In patients receiving propranolol, the percent of predicted HR was significantly lower and persisted up to a year postburn; however, significant reductions in REE and RPP were only sustained through 6 months, while no difference was seen at 1 year.

A large clinical trial evaluated propranolol's effects on cardiac function when started $24-72 \mathrm{~h}$ after admission versus control in 406 children with burns $>30 \%$ of TBSA (Williams et al., 2011). CO decreased after 2 weeks of starting propranolol and the reduction continued throughout the trial. SV, when compared to non-burned children of the same age, was higher in patients receiving propranolol versus control (112 $\pm 8 \%$ vs. $94 \pm 5 \%$; $p<$ 0.02 ), likely a function of the reduced HR allowing for longer ventricular filling times. RPP decreased in the group receiving propranolol, indicating lower myocardial oxygen consumption. These results suggest that propranolol has a significant hemodynamic impact on pediatric burn patients.

Data for $\beta \mathrm{B}$ use in burned adults are limited, but the available evidence supports conclusions comparable to these pediatric studies. Arbabi et al. (Arbabi et al., 2004) compared three cohorts: preexisting $\beta \mathrm{B}$ use continued during hospitalization, new hospital $\beta B$ use, and no $\beta B$ use in adult burn patients. Unlike the pediatric studies, $\beta B$ selection varied with most receiving metoprolol, atenolol, and esmolol, and few receiving propranolol. Preexisting $\beta B$ was associated with a significantly lower rate of mortality than $\beta \mathrm{B}$ initiation during hospitalization and no $\beta \mathrm{B}$ ( 5 vs. $27 \%$ and $13 \%$, respectively). The higher mortality rate in the hospital-initiated $\beta \mathrm{B}$ group may be due to the presence of tachyarrhythmias treated with $\beta \mathrm{B}$ and more severe underlying disease, which was supported by prolonged ICU and hospital stays in the group. Preexisting $\beta \mathrm{B}$ was associated with a shorter mean healing time of 21 days when compared to control $(p=$ 0.02 ). These data suggest antecedent $\beta B$ use may confer a lower risk of mortality and accelerated healing time, which complements the data for improved outcomes in other adrenergic stress states like sepsis.

In 2009, Mohammadi et al. (Mohammadi et al., 2009) randomized 79 adult burn patients to propranolol or control and assessed wound healing dynamics. Patients receiving propranolol had more rapid healing times and reductions in required graft size ( 13.75 vs $18.75 \% ; p=0.006)$ in addition to shorter hospital length of stay (24.41 vs 30.95 days; $p=0.05)$. To build on these results, Ali et al. (Ali et al., 2015) evaluated the effect of propranolol on wound healing and blood loss in a cohort of 69 adult burn patients. Patients receiving propranolol initiated within $48 \mathrm{~h}$ of admission had a shorter recovery time with an average of $10 \pm 5$ days in between skin grafting procedures, whereas patients in the control group had an average of $17 \pm$ 12 days in between procedures $(p=0.02)$. When hematocrit levels were drawn perioperatively, patients receiving propranolol showed a $5-7 \%$ increase compared to control $(p=$ $0.002)$. Notably, the propranolol patients required larger grafts, but no differences in blood transfusions were observed, thus concluding the utility of propranolol for diminishing blood loss during skin graft procedures and improving wound healing. Further investigation in a recent Pakistani clinical trial of propranolol in 70 patients started day three post-burn demonstrated similar reductions in healing time (about a 1 week reduction) and time to graft readiness (10 days reduction) (Cheema et al., 2020). Propranolol also resulted in shorter hospitalization (26.7 vs. 33.6 days; $p<0.001$ ).

Overall, the evidence suggest $\beta \mathrm{B}$ are effective in improving burn recovery in both pediatric and adult patients. By mitigating the adrenergic response at early time points after burns, $\beta \mathrm{B}$ can lessen the negative effects of the hyperadrenergic burn state. The 2012 American Burn Association (ABA) Burn Quality Consensus Conference Summary agreed that $\beta B$ use is beneficial in pediatric and adult burn patients but recommended further research due to the lack of level one evidence at that time (Gibran et al., 2013). The International Society for Burn Injuries (ISBI) released the Practice Guidelines for Burn Care, Part 2 in 2018 with a recommendation to use a nonselective $\beta \mathrm{B}$ in burn patients $\leq 18$ years old with the goal of reducing HR to $75 \%$ of the admission HR (Allorto et al., 2018). Since the publication of the ISBI guidelines in 2018, there has been no new evidence in pediatric burn patients; however, the Cheema et al. trial in Pakistan provides additional, robust evidence in adult burn patients which may lead to increased guidance in this population. While these guideline statements do make recommendations for $\beta \mathrm{B}$ use and monitoring including $\mathrm{HR}$ and weight loss, they do not specify timing or dosing. Based on the studies evaluated, propranolol initiated within one to 3 days after burn injury has the strongest evidence in both children and adults.

Overall, the evidence suggest $\beta \mathrm{B}$ are effective in improving burn recovery in both pediatric and adult patients. By mitigating the adrenergic response at early time points after burns, $\beta \mathrm{B}$ can lessen the negative effects of the hyperadrenergic burn state. Dosing evaluated in these studies with the strongest evidence in both children and adults was propranolol $1-3 \mathrm{mg} / \mathrm{kg} /$ day within one to 3 days after burn injury and titrated based on 
hemodynamic effects. Adults maintained on another $\beta \mathrm{B}$ agent may be better served continuing their current $\beta B$ instead of switching to propranolol; however, no evidence has addressed head-to-head comparisons of $\beta \mathrm{B}$ providing an area for future research.

\section{Traumatic Brain Injury}

Following traumatic brain injury (TBI), a systemic hyperadrenergic state develops characterized by adrenal release of catecholamines and sympathetic activation (Clifton et al., 1981). The surge in catecholamine levels causes vasoconstriction, worsened cerebral ischemia, increased intracranial pressure, all leading to ongoing secondary injury to brain tissue (Lazaridis, 2017; Rizoli et al., 2017). $\beta \mathrm{B}$ can theoretically inhibit the catecholamine interaction with beta adrenergic receptors thus obstructing the detrimental sympathetic nervous system hyperactivity associated with severe TBI. Benefit may also be seen from $\beta \mathrm{B}$ by decreasing the cerebral oxygen demand, thus improving relative ischemia (Clifton et al., 1981).

Substantial pre-clinical evidence has collectively found that $\beta \mathrm{B}$ reduce cerebral ischemia and increase cerebral perfusion following traumatic insult (Goyagi et al., 2006; Ley et al., 2009; Goyagi et al., 2010; Iwata et al., 2010; Ley et al., 2010; Umehara et al., 2010; Goyagi et al., 2012; Song et al., 2014). Neurological deficit scores and infarct volumes were decreased in rats or mice that were treated with $\beta \mathrm{B}$. Differences in the route of administration, agent chosen, dose, and timing varied but globally use of $\beta B$ appears to confer benefit. Propranolol (Goyagi et al., 2006; Ley et al., 2009; Iwata et al., 2010; Ley et al., 2010), esmolol (Goyagi et al., 2006; Goyagi et al., 2010; Iwata et al., 2010; Umehara et al., 2010; Goyagi et al., 2012), landiolol (Goyagi et al., 2006; Goyagi et al., 2010; Iwata et al., 2010; Umehara et al., 2010; Goyagi et al., 2012), carvedilol (Goyagi et al., 2006), and betaxalol (Song et al., 2014) have all been investigated. Goyagi et al. (Goyagi et al., 2006) found no difference between intravascular versus intrathecal administration, Song et al. (Song et al., 2014) only investigated intraventricular administration, and all other studies used intravascular administration. Iwata et al. was the only study to indicate medication preference where esmolol and landiolol showed superior neuroprotection compared to propranolol in postischemic treatment. (Iwata et al., 2010). Higher doses of propranolol $(4 \mathrm{mg} / \mathrm{kg})$ were preferred to lower doses $(1 \mathrm{mg} / \mathrm{kg})$ (Ley et al., 2010), while no difference was observed amongst varying doses of esmolol and landiolol (Goyagi et al., 2012). Conflicting evidence exists for the timing of $\beta \mathrm{B}$ administration, where Ley et al. (Ley et al., 2010) observed that initiation of $\beta B$ treatment pre-TBI was equivalent to post-TBI while Iwata (Iwata et al., 2010) found only post-TBI initiation benefit.

To date, only one RCT regarding beta-blocker use in TBI has been conducted by Cruickshank et al. (Cruickshank et al., 1987) Secondary to unclear randomization and allocation concealment method in addition to incomplete outcome data reported, the trial has largely been discounted due to a high risk of bias; however, it did show a positive correlation between arterial noradrenaline concentration and cardiac damage. (Cruickshank et al., 1987) (Alali et al., 2017) Additionally, fewer $\beta \mathrm{B}$-group patients experienced supraventricular tachycardia (6 vs. 28; $p<0.0001$ ) and ST-segment and T-wave changes (15 vs. $26 ; p=0.062$ ). $\beta \mathrm{B}$ use also inhibited further increases in myocardial isoenzyme of creatine kinase (CKMB) and abolished focal myocardial necrotic lesions compared to placebo. The remainder of the clinical evidence regarding $\beta \mathrm{B}$ use in TBI is from one multi-institutional, prospective, observational study and nine observational cohort studies, but overwhelmingly, this evidence concludes a mortality benefit for use of $\beta$ B in TBI (Alali et al., 2017; Chen et al., 2017).

Within the nine retrospective cohort studies conducted, eight analyzed a primary outcome of in-hospital mortality (Arbabi et al., 2007; Cotton et al., 2007; Inaba et al., 2008; Schroeppel et al., 2010; Schroeppel et al., 2014; Mohseni et al., 2015; Ko et al., 2016; Murry et al., 2016; Zangbar et al., 2016). After adjustments, $\beta$ B use after TBI was associated with statistically significant lower mortality in seven out of the eight studies with primary outcomes of in-hospital mortality (Arbabi et al., 2007; Cotton et al., 2007; Inaba et al., 2008; Schroeppel et al., 2010; Mohseni et al., 2015; Ko et al., 2016; Zangbar et al., 2016). Schroeppel et al. (Schroeppel et al., 2014) showed similar adjusted odds of mortality amongst all subjects, but subgroup analysis revealed lower odds of mortality in patients who received propranolol. The $\beta \mathrm{B}$ cohorts typically were comprised of older subjects (Arbabi et al., 2007; Inaba et al., 2008; Schroeppel et al., 2010; Mohseni et al., 2015) with more severe head injuries (Arbabi et al., 2007; Inaba et al., 2008; Schroeppel et al., 2010; Mohseni et al., 2015) as indicated by lower GCS levels (Arbabi et al., 2007; Ko et al., 2016) and therefore investigators adjusted for potential confounding factors. In-hospital mortality was a secondary outcome in Murry et al. (Murry et al., 2016) where no difference was observed, although no adjustments were made. A meta-analysis of all nine cohort studies, which included 8,245 patients, revealed a statistically significant mortality reduction when patients were exposed to beta-blockers after TBI (pooled OR $=0.39 ; p<$ 0.00001) (Alali et al., 2017). In all of the cohort studies, $\beta B$ were initiated during hospital stay after the TBI had occurred and continued for varied durations. Two of the more recent studies from 2016 made an effort to administer propranolol earlier in the time course (within twelve (Murry et al., 2016) or twenty-four (Ko et al., 2016) hours of admission). Various $\beta \mathrm{B}$ were used amongst the studies with no preference cited between agents except in the aforementioned Schroeppel et al. study where propranolol reduced mortality compared to atenolol, carvedilol, esmolol, labetalol, metoprolol, and sotalol (Schroeppel et al., 2014). In 2017, based on a meta-analysis of these observational cohort studies, the Eastern Association of Surgery and Trauma (EAST), made a conditional recommendation for in-hospital use of $\beta B$ in adults admitted to the ICU with severe, acute TBI and no contraindications to $\beta \mathrm{B}$ (Alali et al., 2017). The recommendation requires that hypotension (systolic blood pressure [SBP] $<90 \mathrm{mmHg}$ ) and symptomatic bradycardia $(\mathrm{HR}<50 \mathrm{bpm})$ are avoided, but there is no formal recommendation on when to initiate $\beta B$, which $\beta B$ to use, and how to titrate the $\beta B$ therapy (Alali et al., 2017). In general, hypotension should warrant $\beta \mathrm{B}$ discontinuation or dose reduction. 
In 2018, to build on the optimistic findings of these small single-center trials, the American Association for the Surgery of Trauma (AAST) conducted a multi-institutional, prospective observational trial (Ley et al., 2018). After analysis of 2,252 patients, the trial concluded that patients who received $\beta B$ after TBI had a significantly lower adjusted (adjusted OR = $0.35 ; p<0.001)$ and unadjusted mortality rate (13.8 vs. $17.7 \%$; $p=0.013)$ in congruence with the 2017 EAST guideline recommendation. Further investigation revealed a reduction in mortality associated with propranolol use compared to all other $\beta B$ (9.3 vs. $15.9 \% ; p=0.003$ ). This study revealed no difference in neurological outcomes associated with $\beta \mathrm{B}$ use and patients who received propranolol had increased length of stay despite the aforementioned survival advantage.

NCT02957331, a randomized, open-label interventional trial, released study results on June 4, 2020 investigating the use of propranolol after TBI (Rizoli et al., 2017). The results show a difference of $7.7 \%$ propranolol arm versus $33.33 \%$ nonpropranolol arm for all-cause 30-days mortality, although no analysis has been published. Propranolol was dosed to target a HR $<100 \mathrm{bpm}$ and was held if the patient became hypotensive (SBP $<100 \mathrm{mmHg}$ ) or bradycardic (HR $<60 \mathrm{bpm}$ ). The DASH After TBI trial (NCT01322048) is an ongoing, randomized, doubleblind trial comparing propranolol and clonidine use to placebo (Patel et al., 2012). The primary outcome is ventilator-free days supplemented by multiple secondary outcomes, including allcause mortality and neuropsychological outcomes. Interim data demonstrates decreased ventilator-free days and decreased percentage of all-cause mortality associated with adrenergic blockade (propranolol and clonidine) (Ley et al., 2009). No neuropsychological outcomes have been reported at this time. Only one propensity-matched case control study has addressed neuropsychological outcomes thus far, where beta-blockade was associated with shorter length of hospital stay and reduced risk of poor long-term functional outcome (Ahl et al., 2017).

In summary, $\beta B$ use after TBI has been associated with decreased in-hospital mortality in one multi-institutional, prospective, observational trial, and nine retrospective cohort studies. Only one RCT has been conducted where mortality was not investigated; however, existing evidence supports the most recent 2017 EAST guideline recommendations of using $\beta B$ following TBI. Studies evaluated a variety of both selective and nonselective $\beta \mathrm{B}$ in patients with a TBI; however, dosing was not reported in a majority of cases. Continued investigation in more robust trial designs may aid with clarification of preferred agent, dosing, titration, timing for initiation.

\section{Cardiac Arrest}

Epinephrine is part of the algorithm to treat pulseless ventricular tachycardia (VT) and ventricular fibrillation (VF) (Panchal et al., 2020); however, epinephrine, itself a catecholamine, can increase oxygen requirement of an already strained heart and may potentiate VF risk (Monroe and French, 1960). Thus, in addition to endogenous catecholamine release that can occur during ischemia, the cycle of catecholamine administration during VF may lead to refractory VF (RVF) or electrical storm (Nademanee et al., 2000; Lee et al., 2016). $\beta$ B have been hypothesized to improve outcomes in VF by inhibiting elevated catecholamine levels to decrease myocardial oxygen demand and lower the threshold for VF (Lee et al., 2016). Animal studies have shown that $\beta B$ have improved rates of resuscitation when used in cardiac arrest (Ditchey et al., 1994; Cammarata et al., 2004; Huang et al., 2004; Killingsworth et al., 2004). Several small trials evaluated the use of $\beta B$ in refractory VF and electrical storm treatment and concluded that their use increases the rates of ROSC and overall survival (Nademanee et al., 2000; Skrifvars et al., 2003; Driver et al., 2014; Lee et al., 2016).

A small study evaluated the use of esmolol versus control on the incidence of sustained ROSC in patients with RVF (Lee et al., 2016). Sustained ROSC was greater in patients who received esmolol compared with those in the control group (56 vs. $16 \%$; $p=0.007)$. Although there were significantly more patients who received esmolol that survived to ICU admission, survival and neurological outcome at 30 days, 3 months, and 6 months was not significant $(p=0.36)$. Similarly, Driver et al. (Driver et al., 2014) assessed the outcomes of 6 patients receiving esmolol versus 19 control patients who had RVF that started as VT or VF either outside of the hospital or in the emergency department. Patients in the esmolol group had greater incidence of sustained ROSC (67 vs. $32 \%$ ) and survival to ICU admission (66 vs. $32 \%$ ). Differing from the previous trial, patients receiving esmolol in this study had increased frequencies of survival to hospital discharge (50 vs. 16\%) and discharge with fair neurologic outcome (50 vs. 11\%), although these results were not statistically significant due to small sample size.

Nademanee et al. (Nademanee et al., 2000) studied the effects of sympathetic blockade in 27 patients vs. anti-arrhythmic agents in 22 patients with electrical storm. These patients had a myocardial infarction between $72 \mathrm{~h}$ and 3 months prior to developing electrical storm. Patients in the sympathetic blockade group received either propranolol, esmolol, or left stellate ganglionic blockade (LSGB). Because patients receiving beta blockers were analyzed in a combined group with those receiving LSGB, this limits our interpretation of the statistical analyses from the trial. No subgroup analysis of $\beta B$ use alone was presented. Patients in the control group received lidocaine, procainamide, and/or bretylium tosylate as the anti-arrhythmic agent. Patients receiving a sympathetic blocker had a significantly higher survival rate at 1 week than patients who received an antiarrhythmic ( 22 vs. $82 \%$; $p<0.0001$ ). Survival rate at 1 year was also greater in patients who received a sympathetic blocker versus an anti-arrhythmic ( 67 vs. $5 \% ; p<0.0001$ ).

These three studies by Lee et al. (Lee et al., 2016), Driver et al. (Driver et al., 2014), and Nademanee et al. (Nademanee et al., 2000) were recently analyzed in a systematic review and metaanalysis by Gottlieb et al. (Gottlieb et al., 2020) Cumulatively, 115 patients were included with similar results to the individual studies of beta-blockade association with improved outcomes ranging from ROSC to survival with favorable neurologic outcome. The risk of bias was considered moderate to severe given the influence of confounding factors and selection of participants.

Propranolol was compared to metoprolol for electrical storm in combination with amiodarone for patients who had congestive 
heart failure and an implantable cardioverter-defibrillator (ICD) to assess the last VT or VF event that required the ICD for arrhythmia termination (Chatzidou et al., 2018). Patients receiving propranolol had 2.67 times fewer events of VT or VF ( $p=0.001)$, as well as 2.34 times less incidences of ICD firings $(p=0.004)$. After $24 \mathrm{~h}$, more patients receiving propranolol than metoprolol had not had an arrhythmia $(p=$ 0.03). Propranolol was associated with higher likelihood of arrhythmia termination $(p<0.001)$, faster arrhythmia termination $(p<0.05)$, and decreased hospital length of stay when compared to metoprolol $(p<0.05)$. As such, non-selective $\beta 1$ and $\beta 2$ blockade appeared to result in more significant decreases in catecholamines and cardiac norepinephrine spillover leading to improvements in electrical storm control, whereas $\beta 1$-selective blockers have been associated with increased cardiac norepinephrine spillover.

Metoprolol was also studied in patients resuscitated from outof-hospital VF in a forward multiple logistic regression analysis to predict survival conducted by Skrifvars et al.(Skrifvars et al., 2003) Out of 102 patients total, 79 received beta-blocking agents (80\%) which included the use of either metoprolol (intravenous or oral) or bisoprolol (oral). $\beta \mathrm{B}$ use during the first $72 \mathrm{~h}$ of postresuscitation care was associated with survival at 6 months from the event in both the univariate $(p<0.001)$ and multiple logistic regression analyses $(p=0.002)$.

The 2017 AHA/ACC/HRS Guideline for the Management of Patients with Ventricular Arrythmias and Prevention of Sudden Cardiac Death (SCD) support the use of $\beta B$ as first-line antiarrhythmic therapy for the treatment of ventricular arrhythmias and reducing the risk of SCD (Al-Khatib et al., 2018). Additionally, $\beta B$ use is associated with a significant reduction in mortality in the setting of acute myocardial infarction (AMI) in addition to suppressing recurrent VF in patients with recent MI. The 2018 AHA Focused Update on ACLS Use of Antiarrhythmic Drugs During and Immediately After Cardiac Arrest does not recommend $\beta B$ use immediately following cardiac arrest given limited evidence (Panchal et al., 2018). Upon review, esmolol 300-500 $\mu \mathrm{g} / \mathrm{kg}$ loading dose followed by $0-100 \mu \mathrm{g} / \mathrm{kg} / \mathrm{min}$ infusion was the most evaluated $\beta \mathrm{B}$ in the cardiac arrest studies, but propranolol, bisoprolol and metoprolol at variable doses were additionally studied. There is also some controversy as one study used a loading dose of esmolol $300-500 \mu \mathrm{g} / \mathrm{kg}$ while another studied esmolol $300-500 \mathrm{mg} / \mathrm{kg}$ accounting for a substantial one-thousandfold difference.

\section{REFERENCES}

Ahl, R., Thelin, E. P., Sjölin, G., Bellander, B. M., Riddez, L., Talving, P., et al. (2017). $\beta$-Blocker after Severe Traumatic Brain Injury Is Associated with Better Long-Term Functional Outcome: a Matched Case Control Study. Eur. J. Trauma Emerg. Surg. 43 (6), 783-789. doi:10.1007/s00068-017-0779-5

Al-Khatib, S. M., Stevenson, W. G., Ackerman, M. J., Bryant, W. J., Callans, D. J., Curtis, A. B., et al. (2018). 2017 AHA/ACC/HRS Guideline for Management of Patients with Ventricular Arrhythmias and the Prevention of Sudden Cardiac Death: A Report of the American College of Cardiology/American Heart Association Task Force on Clinical Practice Guidelines and the Heart
In summary, Tthe demonstration of improved rates of ROSC and sustained outcomes in addition to increased survival from $\beta B$ (most notably with esmolol) use in patients with RVF is promising; however, larger studies are necessary to offer increased guidance on $\beta \mathrm{B}$ use during and after cardiac arrest in the coming years. Furthermore, additional research is needed to compare specific $\beta \mathrm{B}$ agents in cardiac arrest to build on existing evidence that non-selective agents may lead to fewer arrhythmias, improved arrhythmia termination, and decreased hospital length of stay when compared to $\beta 1$-selective $\beta \mathrm{B}$. However, once hemodynamic stabilization is achieved, current evidence is in line with guideline recommendations to initiate $\beta \mathrm{B}$ therapy to reduce risk of repeated VF (Al-Khatib et al., 2018).

\section{CONCLUSION}

Although negative inotropes appear counterintuitive in hemodynamically compromised critical illness, dampening catecholamine signaling may confer a wide range of benefits, dependent on etiology. In Sepsis, immediately post fluid resuscitation and initial stabilization, re-initiation of home $\beta B$ therapy should be strongly considered. Additionally, existing evidence suggests $\beta B$ use may improve recovery following burn injury, reduce mortality rate in TBI, and increase achievement of ROSC in RVF cardiac arrest. Further, promising new data in sepsis suggest a potential role as well as further inquiry.

\section{AUTHOR CONTRIBUTIONS}

All authors participated in drafting and critical revisions. TJ/AN participated in conceptualization and planning.

\section{FUNDING}

This work was supported by the National Center for Advancing Translational Sciences (NCATS) of the National Institutes of Health (NIH) under Award Numbers UL1TR002378 and KL2TR002381 awarded to AN and the UL1TR002378 and TL1TR002382 awarded to TJ.

Rhythm Society. Circulation 138(13), e272-e391. doi: doi:doi:10.1161/ CIR.0000000000000549

Alali, A. S., Mukherjee, K., McCredie, V. A., Golan, E., Shah, P. S., Bardes, J. M., et al. (2017). Beta-blockers and Traumatic Brain Injury: A Systematic Review, Meta-Analysis, and Eastern Association for the Surgery of Trauma Guideline. Ann. Surg. 266 (6), 952-961. doi:10.1097/SLA.0000000000002286

Ali, A., Herndon, D. N., Mamachen, A., Hasan, S., Andersen, C. R., Grogans, R. J., et al. (2015). Propranolol Attenuates Hemorrhage and Accelerates Wound Healing in Severely Burned Adults. Crit. Care 19, 217. doi:10.1186/s13054-015-0913-x

Allorto, N., Atieh, B., Bolgiani, A., Chatterjee, P., Cioffi, W., Dziewulski, P., et al. (2018). ISBI Practice Guidelines for Burn Care, Part 2. Burns 44 (7), 1617-1706. doi:10.1016/j.burns.2018.09.012 
Arbabi, S., Ahrns, K. S., Wahl, W. L., Hemmila, M. R., Wang, S. C., Brandt, M. M., et al. (2004). Beta-blocker Use Is Associated with Improved Outcomes in Adult Burn Patients. J. Trauma 56 (2), 265-271. discussion 269-271. doi:10.1097/ 01.TA.0000109859.91202.C8

Arbabi, S., Campion, E. M., Hemmila, M. R., Barker, M., Dimo, M., Ahrns, K. S., et al. (2007). Beta-blocker Use Is Associated with Improved Outcomes in Adult Trauma Patients. J. Trauma 62 (1), 56-62. doi:10.1097/TA.0b013e31802d972b

Balik, M., Rulisek, J., Leden, P., Zakharchenko, M., Otahal, M., Bartakova, H., et al. (2012). Concomitant Use of Beta-1 Adrenoreceptor Blocker and Norepinephrine in Patients with Septic Shock. Wien Klin Wochenschr 124 (15-16), 552-556. doi:10.1007/s00508-012-0209-y

Baron, P. W., Barrow, R. E., Pierre, E. J., and Herndon, D. N. (1997). Prolonged Use of Propranolol Safely Decreases Cardiac Work in Burned Children. J. Burn Care Rehabil. 18 (3), 223-227. doi:10.1097/ 00004630-199705000-00008

Belletti, A., Landoni, G., Lomivorotov, V. V., Oriani, A., and Ajello, S. (2020). Adrenergic Downregulation in Critical Care: Molecular Mechanisms and Therapeutic Evidence. J. Cardiothorac. Vasc. Anesth. 34 (4), 1023-1041. doi:10.1053/j.jvca.2019.10.017

Benedict, C. R., and Rose, J. A. (1992). Arterial Norepinephrine Changes in Patients with Septic Shock. Circ. Shock 38 (3), 165-172.

Berk, J. L., Hagen, J. F., Maly, G., and Koo, R. (1972). The Treatment of Shock with Beta Adrenergic Blockade. Arch. Surg. 104 (1), 46-51. doi:10.1001/ archsurg.1972.04180010040011

Bignami, E., Guarnieri, M., Franco, A., Gerli, C., De Luca, M., Monaco, F., et al. (2017). Esmolol before cardioplegia and as cardioplegia adjuvant reduces cardiac troponin release after cardiac surgery. A randomized trial. Perfusion 34 (2), 313-320. doi:10.1177/0267659116681437

Boldt, J., Menges, T., Kuhn, D., Diridis, C., and Hempelmann, G. (1995). Alterations in Circulating Vasoactive Substances in the Critically Ill-Aa Comparison between Survivors and Non-survivors. Intensive Care Med. 21 (3), 218-225. doi:10.1007/BF01701475

Bosch, N. A., Rucci, J. M., Massaro, J. M., Winter, M. R., Quinn, E. K., Chon, K. H., et al. (2021). Comparative Effectiveness of Heart Rate Control Medications for the Treatment of Sepsis-Associated Atrial Fibrillation. Chest 159, 1452-1459. doi:10.1016/j.chest.2020.10.049

Bosmann, M., Grailer, J. J., Zhu, K., Matthay, M. A., Sarma, J. V., Zetoune, F. S., et al. (2012). Anti-inflammatory Effects of $\beta 2$ Adrenergic Receptor Agonists in Experimental Acute Lung Injury. Faseb $j 26$ (5), 2137-2144. doi:10.1096/fj.11201640

Bristow, M. R., Ginsburg, R., Umans, V., Fowler, M., Minobe, W., Rasmussen, R., et al. (1986). Beta 1- and Beta 2-Adrenergic-Receptor Subpopulations in Nonfailing and Failing Human Ventricular Myocardium: Coupling of Both Receptor Subtypes to Muscle Contraction and Selective Beta 1-receptor DownRegulation in Heart Failure. Circ. Res. 59 (3), 297-309. doi:10.1161/ 01.res.59.3.297

Butler, J., Young, J. B., Abraham, W. T., Bourge, R. C., Adams, K. F., Clare, R., et al. (2006). Beta-Blocker Use and Outcomes Among Hospitalized Heart Failure Patients. J. Amer. College Cardiol. 47 (12), 2462-2469. doi:10.1016/ j.jacc. 2006.03.030

Cain, B. S., Meldrum, D. R., Dinarello, C. A., Meng, X., Joo, K. S., Banerjee, A., et al. (1999). Tumor Necrosis Factor-Alpha and Interleukin-1beta Synergistically Depress Human Myocardial Function. Crit. Care Med. 27 (7), 1309-1318. doi:10.1097/00003246-199907000-00018

Cammarata, G., Weil, M. H., Sun, S., Tang, W., Wang, J., and Huang, L. (2004). Beta1-adrenergic Blockade during Cardiopulmonary Resuscitation Improves Survival. Crit. Care Med. 32 (9 Suppl. 1), S440-S443. doi:10.1097/ 01.ccm.0000134263.32657.34

Carstairs, J. R., Nimmo, A. J., and Barnes, P. J. (1985). Autoradiographic Visualization of Beta-Adrenoceptor Subtypes in Human Lung. Am. Rev. Respir. Dis. 132 (3), 541-547. doi:10.1164/arrd.1985.132.3.541

Chacko, C. J., and Gopal, S. (2015). Systematic Review of Use of $\beta$-blockers in Sepsis. J. Anaesthesiol Clin. Pharmacol. 31 (4), 460-465. doi:10.4103/0970-9185.169063 Chatzidou, S., Kontogiannis, C., Tsilimigras, D. I., Georgiopoulos, G., Kosmopoulos, M., Papadopoulou, E., et al. (2018). Propranolol versus Metoprolol for Treatment of Electrical Storm in Patients with Implantable Cardioverter-Defibrillator. J. Am. Coll. Cardiol. 71 (17), 1897-1906. doi:10.1016/j.jacc.2018.02.056
Cheema, S. A., Ahmed, U. T., Nasir, H., Dogar, S. R., and Mustafa, Z. (2020). Effects of Propranolol in Accelerating Wound Healing and Attenuation of Hypermetabolism in Adult Burn Patients. J. Coll. Physicians Surg. Pak 30 (1), 46-50. doi:10.29271/jcpsp.2020.01.46

Chen, Z., Tang, L., Xu, X., Wei, X., Wen, L., and Xie, Q. (2017). Therapeutic Effect of Beta-Blocker in Patients with Traumatic Brain Injury: A Systematic Review and Meta-Analysis. J. Crit. Care 41, 240-246. doi:10.1016/j.jcrc.2017.05.035

Chruscinski, A. J., Rohrer, D. K., Schauble, E., Desai, K. H., Bernstein, D., and Kobilka, B. K. (1999). Targeted Disruption of the Beta2 Adrenergic Receptor Gene. J. Biol. Chem. 274 (24), 16694-16700. doi:10.1074/jbc.274.24.16694

Clifton, G. L., Ziegler, M. G., and Grossman, R. G. (1981). Circulating Catecholamines and Sympathetic Activity after Head Injury. Neurosurgery 8 (1), 10-14. doi:10.1227/00006123-198101000-00003

Coppola, S., Froio, S., and Chiumello, D. (2015). $\beta$-Blockers in Critically Ill Patients: from Physiology to Clinical Evidence. Crit. Care 19 (1), 119. doi:10.1186/s13054-015-0803-2

Cotton, B. A., Snodgrass, K. B., Fleming, S. B., Carpenter, R. O., Kemp, C. D., Arbogast, P. G., et al. (2007). Beta-blocker Exposure Is Associated with Improved Survival after Severe Traumatic Brain Injury. J. Trauma 62 (1), 26-35. doi:10.1097/TA.0b013e31802d02d0

Cruickshank, J. M., Neil-Dwyer, G., Degaute, J. P., Hayes, Y., Kuurne, T., Kytta, J., et al. (1987). Reduction of Stress/catecholamine-Induced Cardiac Necrosis by Beta 1-selective Blockade. Lancet 2 (8559), 585-589. doi:10.1016/s01406736(87)92984-9

de Lucia, C., Eguchi, A., and Koch, W. J. (2018). New Insights in Cardiac $\beta$-Adrenergic Signaling during Heart Failure and Aging. Front. Pharmacol. 9, 904. doi:10.3389/fphar.2018.00904

de Prost, N., Dreyfuss, D., Ricard, J. D., and Saumon, G. (2008). Terbutaline Lessens Protein Fluxes across the Alveolo-Capillary Barrier during High-Volume Ventilation. Intensive Care Med. 34 (4), 763-770. doi:10.1007/s00134-007-0954-y

Ditchey, R. V., Rubio-Perez, A., and Slinker, B. K. (1994). Beta-adrenergic Blockade Reduces Myocardial Injury during Experimental Cardiopulmonary Resuscitation. J. Am. Coll. Cardiol. 24 (3), 804-812. doi:10.1016/07351097(94)90032-9

Dransfield, M. T., Voelker, H., Bhatt, S. P., Brenner, K., Casaburi, R., Come, C. E., et al. (2019). Metoprolol for the Prevention of Acute Exacerbations of COPD. N. Engl. J. Med. 381 (24), 2304-2314. doi:10.1056/NEJMoa1908142

Driver, B. E., Debaty, G., Plummer, D. W., and Smith, S. W. (2014). Use of Esmolol after Failure of Standard Cardiopulmonary Resuscitation to Treat Patients with Refractory Ventricular Fibrillation. Resuscitation 85 (10), 1337-1341. doi:10.1016/j.resuscitation.2014.06.032

Du, W., Wang, X. T., Long, Y., and Liu, D. W. (2016). Efficacy and Safety of Esmolol in Treatment of Patients with Septic Shock. Chin. Med. J. (Engl) 129 (14), 1658-1665. doi:10.4103/0366-6999.185856

Dünser, M. W., and Hasibeder, W. R. (2009). Sympathetic Overstimulation during Critical Illness: Adverse Effects of Adrenergic Stress. J. Intensive Care Med. 24 (5), 293-316. doi:10.1177/0885066609340519

El Ayadi, A., Prasai, A., Jay, J., Bhattari, N., Guilory, A., Herndon, D., et al. (2019). The Role of Beta-2 Adrenergic Receptors in Cardiac Bioenergetics Following Severe Burns. FASEB J. 33 (S1), lb281. doi:10.1096/ fasebj.2019.33.1_supplement.lb281

Fuchs, C., Wauschkuhn, S., Scheer, C., Vollmer, M., Meissner, K., Kuhn, S. O., et al. (2017). Continuing Chronic Beta-Blockade in the Acute Phase of Severe Sepsis and Septic Shock Is Associated with Decreased Mortality Rates up to 90 Days. Br. J. Anaesth. 119 (4), 616-625. doi:10.1093/bja/aex231

Furian, T., Aguiar, C., Prado, K., Ribeiro, R. V., Becker, L., Martinelli, N., et al. (2012). Ventricular Dysfunction and Dilation in Severe Sepsis and Septic Shock: Relation to Endothelial Function and Mortality. J. Crit. Care 27 (3), 319.e9-15. doi:10.1016/j.jcrc.2011.06.017

Gao Smith, F., Perkins, G. D., Gates, S., Young, D., McAuley, D. F., Tunnicliffe, W., et al. (2012). Effect of Intravenous $\beta$-2 Agonist Treatment on Clinical Outcomes in Acute Respiratory Distress Syndrome (Balti-2): a Multicentre, Randomised Controlled Trial. Lancet 379 (9812), 229-235. doi:10.1016/s0140-6736(11) 61623-1

Gibran, N. S., Wiechman, S., Meyer, W., Edelman, L., Fauerbach, J., Gibbons, L., et al. (2013). Summary of the 2012 ABA Burn Quality Consensus Conference. J. Burn Care Res. 34 (4), 361-385. doi:10.1097/BCR.0b013e31828cb249 
Giembycz, M. A., and Newton, R. (2006). Beyond the dogma: novel $\beta_{2^{-}}$ adrenoceptor signalling in the airways. European Respiratory J. 27 (6), 1286-1306. doi:10.1183/09031936.06.00112605

Gore, D. C., and Wolfe, R. R. (2006). Hemodynamic and Metabolic Effects of Selective Betal Adrenergic Blockade during Sepsis. Surgery 139 (5), 686-694. doi:10.1016/j.surg.2005.10.010

Gottlieb, M., Dyer, S., and Peksa, G. (2020). Reply to: Beta-Blockade for the Treatment of Cardiac Arrest Due to Ventricular Fibrillation or Pulseless Ventricular Tachycardia: A Systematic Review and Meta-Analysis. Resuscitation 150, 193-125. doi:10.1016/j.resuscitation.2019.11.01910.1016/ j.resuscitation.2020.02.020

Goyagi, T., Horiguchi, T., Nishikawa, T., Tobe, Y., and Masaki, Y. (2012). Neuroprotective Effects of Selective $\beta-1$ Adrenoceptor Antagonists, Landiolol and Esmolol, on Transient Forebrain Ischemia in Rats; a DoseResponse Study. Brain Res. 1461, 96-101. doi:10.1016/j.brainres.2012.04.040

Goyagi, T., Horiguchi, T., Nishikawa, T., and Tobe, Y. (2010). Post-treatment with Selective $\beta 1$ Adrenoceptor Antagonists Provides Neuroprotection against Transient Focal Ischemia in Rats. Brain Res. 1343, 213-217. doi:10.1016/ j.brainres.2010.04.079

Goyagi, T., Kimura, T., Nishikawa, T., Tobe, Y., and Masaki, Y. (2006). Betaadrenoreceptor Antagonists Attenuate Brain Injury after Transient Focal Ischemia in Rats. Anesth. Analg 103 (3), 658-663. doi:10.1213/ 01.ane.0000228859.95126.69

Guarracino, F., Ferro, B., Morelli, A., Bertini, P., Baldassarri, R., and Pinsky, M. R. (2014). Ventriculoarterial Decoupling in Human Septic Shock. Crit. Care 18 (2), R80. doi:10.1186/cc13842

Gutierrez, J., Hossam, A., Lazarezcu, R., Kay, E., and Rundek, T. (2009). Effect of Beta Blockers on Sepsis Outcome. Med. Sci. Monit. 15 (10), CR499-503.

Guz, D., Buchritz, S., Guz, A., Ikan, A., Babich, T., Daitch, V., et al. (2021). $\beta$-Blockers, Tachycardia, and Survival Following Sepsis: An Observational Cohort Study. Clin. Infect. Dis. 73, e921-e926. doi:10.1093/cid/ciab034

Hagiwara, S., Iwasaka, H., Maeda, H., and Noguchi, T. (2009). Landiolol, an Ultrashort-Acting Beta1-Adrenoceptor Antagonist, Has Protective Effects in an LPS-Induced Systemic Inflammation Model. Shock 31 (5), 515-520. doi:10.1097/SHK.0b013e3181863689

Hajsadeghi, S., Rahbar, M. H., Iranpour, A., Salehi, A., Asadi, O., and Jafarian, S. R. (2018). Dobutamine-induced Takotsubo Cardiomyopathy: A Systematic Review of the Literature and Case Report. Anatol J. Cardiol. 19 (6), 412-416. doi:10.14744/AnatolJCardiol.2018.78642

Hamill, R. W., Woolf, P. D., McDonald, J. V., Lee, L. A., and Kelly, M. (1987). Catecholamines Predict Outcome in Traumatic Brain Injury. Ann. Neurol. 21 (5), 438-443. doi:10.1002/ana.410210504

Hart, D. W., Wolf, S. E., Mlcak, R., Chinkes, D. L., Ramzy, P. I., Obeng, M. K., et al. (2000). Persistence of Muscle Catabolism after Severe Burn. Surgery 128 (2), 312-319. doi:10.1067/msy.2000.108059

Hasegawa, D., Sato, R., Prasitlumkum, N., Nishida, K., Takahashi, K., Yatabe, T., et al. (2021). Effect of Ultrashort-Acting $\beta$-Blockers on Mortality in Patients with Sepsis with Persistent Tachycardia Despite Initial Resuscitation. Chest 159, 2289-2300. doi:10.1016/j.chest.2021.01.009

Herndon, D. N., Hart, D. W., Wolf, S. E., Chinkes, D. L., and Wolfe, R. R. (2001). Reversal of Catabolism by Beta-Blockade after Severe Burns. N. Engl. J. Med. 345 (17), 1223-1229. doi:10.1056/NEJMoa010342

Herndon, D. N., Rodriguez, N. A., Diaz, E. C., Hegde, S., Jennings, K., Mlcak, R. P., et al. (2012). Long-term Propranolol Use in Severely Burned Pediatric Patients: a Randomized Controlled Study. Ann. Surg. 256 (3), 402-411. doi:10.1097/ SLA.0b013e318265427e

Hsueh, W. A., and Law, R. (2003). The central Role of Fat and Effect of Peroxisome Proliferator-Activated Receptor-Gamma on Progression of Insulin Resistance and Cardiovascular Disease. Am. J. Cardiol. 92 (4), 3J-9J. doi:10.1016/s00029149(03)00610-6

Huang, L., Weil, M. H., Cammarata, G., Sun, S., and Tang, W. (2004). Nonselective Beta-Blocking Agent Improves the Outcome of Cardiopulmonary Resuscitation in a Rat Model. Crit. Care Med. 32 (9 Suppl. 1), S378-S380. doi:10.1097/ 01.ccm.0000134266.65164.7c

Inaba, K., Teixeira, P. G., David, J. S., Chan, L. S., Salim, A., Brown, C., et al. (2008). Beta-blockers in Isolated blunt Head Injury. J. Am. Coll. Surg. 206 (3), 432-438. doi:10.1016/j.jamcollsurg.2007.10.005
Iwata, M., Inoue, S., Kawaguchi, M., Nakamura, M., Konishi, N., and Furuya, H. (2010). Posttreatment but Not Pretreatment with Selective BetaAdrenoreceptor 1 Antagonists Provides Neuroprotection in the hippocampus in Rats Subjected to Transient Forebrain Ischemia. Anesth. Analg 110 (4), 1126-1132. doi:10.1213/ANE.0b013e3181d278f7

Jacobi, J. (2002). Pathophysiology of Sepsis. Am. J. Health Syst. Pharm. 59 Suppl 1 (Suppl. 1), S3-S8. doi:10.1093/ajhp/59.suppl_1.S3

January, C. T., Wann, L. S., Alpert, J. S., Calkins, H., Cigarroa, J. E., Cleveland, J. C., et al. (2014). 2014 AHA/ACC/HRS Guideline for the Management of Patients with Atrial Fibrillation: Executive Summary. J. Am. Coll. Cardiol. 64 (21), 2246-2280. doi:10.1016/j.jacc.2014.03.021

Jeschke, M. G., Norbury, W. B., Finnerty, C. C., Branski, L. K., and Herndon, D. N. (2007). Propranolol Does Not Increase Inflammation, Sepsis, or Infectious Episodes in Severely Burned Children. J. Trauma 62 (3), 676-681. doi:10.1097/ TA.0b013e318031afd3

Jones, S. B., and Romano, F. D. (1989). Dose- and Time-dependent Changes in Plasma Catecholamines in Response to Endotoxin in Conscious Rats. Circ. Shock 28 (1), 59-68.

Jones, T. W., Smith, S. E., Van Tuyl, J. S., and Newsome, A. S. (2020). Sepsis With Preexisting Heart Failure: Management of Confounding Clinical Features. J. Intensive Care Med., 885066620928299. doi:10.1177/ 0885066620928299

Kakihana, Y., Nishida, O., Taniguchi, T., Okajima, M., Morimatsu, H., Ogura, H., et al. (2020). Efficacy and Safety of Landiolol, an Ultra-short-acting $\beta 1$-selective Antagonist, for Treatment of Sepsis-Related Tachyarrhythmia (J-Land 3S): a Multicentre, Open-Label, Randomised Controlled Trial. Lancet Respir. Med. 8 (9), 863-872. doi:10.1016/S2213-2600(20)30037-0

Kargin, F., Takir, H. B., Salturk, C., Goksenoglu, N. C., Karabay, C. Y., Mocin, O. Y., et al. (2014). The Safety of Beta-Blocker Use in Chronic Obstructive Pulmonary Disease Patients with Respiratory Failure in the Intensive Care Unit. Multidiscip Respir. Med. 9 (1), 8. doi:10.1186/2049-6958-9-8

Killingsworth, C. R., Wei, C. C., Dell'Italia, L. J., Ardell, J. L., Kingsley, M. A., Smith, W. M., et al. (2004). Short-acting Beta-Adrenergic Antagonist Esmolol Given at Reperfusion Improves Survival after Prolonged Ventricular Fibrillation. Circulation 109 (20), 2469-2474. doi:10.1161/ 01.CIR.0000128040.43933.D3

Ko, A., Harada, M. Y., Barmparas, G., Thomsen, G. M., Alban, R. F., Bloom, M. B., et al. (2016). Early Propranolol after Traumatic Brain Injury Is Associated with Lower Mortality. J. Trauma Acute Care Surg. 80 (4), 637-642. doi:10.1097/ TA.0000000000000959

Lang, C. H., Nystrom, G., and Frost, R. A. (2008). $\beta$-Adrenergic Blockade Exacerbates Sepsis-Induced Changes in Tumor Necrosis Factor $\alpha$ and Interleukin-6 in Skeletal Muscle and Is Associated with Impaired Translation Initiation. J. Trauma Acute Care Surg. 64 (2), 477-486. doi:10.1097/01.TA.0000249375.43015.01

Lazaridis, C. (2017). Cerebral Oxidative Metabolism Failure in Traumatic Brain Injury: "Brain Shock". J. Crit. Care 37, 230-233. doi:10.1016/j.jcrc.2016.09.027

Lee, Y. H., Lee, K. J., Min, Y. H., Ahn, H. C., Sohn, Y. D., Lee, W. W., et al. (2016). Refractory Ventricular Fibrillation Treated with Esmolol. Resuscitation 107, 150-155. doi:10.1016/j.resuscitation.2016.07.243

Lee, Y. R., Seth, M. S., Soney, D., and Dai, H. (2019). Benefits of Beta-Blockade in Sepsis and Septic Shock: A Systematic Review. Clin. Drug Investig. 39 (5), 429-440. doi:10.1007/s40261-019-00762-z

Ley, E. J., Leonard, S. D., Barmparas, G., Dhillon, N. K., Inaba, K., Salim, A., et al. (2018). Beta Blockers in Critically Ill Patients with Traumatic Brain Injury: Results from a Multicenter, Prospective, Observational American Association for the Surgery of Trauma Study. J. Trauma Acute Care Surg. 84 (2), 234-244. doi:10.1097/TA.0000000000001747

Ley, E. J., Park, R., Dagliyan, G., Palestrant, D., Miller, C. M., Conti, P. S., et al. (2010). In Vivo effect of Propranolol Dose and Timing on Cerebral Perfusion after Traumatic Brain Injury. J. Trauma 68 (2), 353-356. doi:10.1097/ TA.0b013e3181c8269a

Ley, E. J., Scehnet, J., Park, R., Schroff, S., Dagliyan, G., Conti, P. S., et al. (2009). The In Vivo Effect of Propranolol on Cerebral Perfusion and Hypoxia after Traumatic Brain Injury. J. Trauma 66 (1), 154-161. discussion 159-161. doi:10.1097/TA.0b013e31819388be

Liu, H., Ding, X. F., Zhang, S. G., Wang, H. X., Luo, Y. G., Duan, X. G., et al. (2019). [Effect of Esmolol in Septic Shock Patients with Tachycardia: a Randomized 
Clinical Trial]. Zhonghua Yi Xue Za Zhi 99 (17), 1317-1322. doi:10.3760/ cma.j.issn.0376-2491.2019.17.009

Liu, P., Wu, Q., Tang, Y., Zhou, Z., and Feng, M. (2018). The Influence of Esmolol on Septic Shock and Sepsis: A Meta-Analysis of Randomized Controlled Studies. Am. J. Emerg. Med. 36 (3), 470-474. doi:10.1016/j.ajem.2017.11.013

Maccari, S., Vezzi, V., Barbagallo, F., Stati, T., Ascione, B., Grò, M. C., et al. (2020). $\beta$-blockers Reverse Agonist-Induced $\beta(2)$-AR Downregulation Regardless of Their Signaling Profile. Int. J. Mol. Sci. 21 (2), 512. doi:10.3390/ijms21020512

Macchia, A., Romero, M., Comignani, P. D., Mariani, J., D’Ettorre, A., Prini, N., et al. (2012). Previous Prescription of $\beta$-blockers Is Associated with Reduced Mortality Among Patients Hospitalized in Intensive Care Units for Sepsis. Crit. Care Med. 40 (10), 2768-2772. doi:10.1097/CCM.0b013e31825b9509

MacNee, W. (2019). Beta-Blockers in COPD - A Controversy Resolved? N. Engl. J. Med. 381 (24), 2367-2368. doi:10.1056/NEJMe1912664

Maris, N. A., de Vos, A. F., Dessing, M. C., Spek, C. A., Lutter, R., Jansen, H. M., et al. (2005). Antiinflammatory Effects of Salmeterol after Inhalation of Lipopolysaccharide by Healthy Volunteers. Am. J. Respir. Crit. Care Med. 172 (7), 878-884. doi:10.1164/rccm.200503-451OC

Maron, M. B., Luther, D. J., Pilati, C. F., Ohanyan, V., Li, T., Koshy, S., et al. (2009). Beta-adrenoceptor Stimulation of Alveolar Fluid Clearance Is Increased in Rats with Heart Failure. Am. J. Physiol. Lung Cel Mol Physiol 297 (3), L487-L495. doi:10.1152/ajplung.90629.2008

Mathieu, C., Zieleskiewicz, L., and Leone, M. (2016). Beta-blockers in Septic Shock: a Magnifying Glass on the Relation Heart Vessel. J. Thorac. Dis. 8 (8), E802-E804. doi:10.21037/jtd.2016.07.12

Mohammadi, A. A., Bakhshaeekia, A., Alibeigi, P., Hasheminasab, M. J., Tolide-ei, H. R., Tavakkolian, A. R., et al. (2009). Efficacy of Propranolol in Wound Healing for Hospitalized Burn Patients. J. Burn Care Res. 30 (6), 1013-1017. doi:10.1097/BCR.0b013e3181b48600

Mohseni, S., Talving, P., Thelin, E. P., Wallin, G., Ljungqvist, O., and Riddez, L. (2015). The Effect of $\beta$-blockade on Survival after Isolated Severe Traumatic Brain Injury. World J. Surg. 39 (8), 2076-2083. doi:10.1007/s00268-0153039-z

Moniotte, S., Belge, C., Sekkali, B., Massion, P. B., Rozec, B., Dessy, C., et al. (2007). Sepsis Is Associated with an Upregulation of Functional Beta3 Adrenoceptors in the Myocardium. Eur. J. Heart Fail. 9 (12), 1163-1171. doi:10.1016/ j.ejheart.2007.10.006

Moniotte, S., Kobzik, L., Feron, O., Trochu, J.-N., Gauthier, C., and Balligand, J.-L. (2001). Upregulation of $\beta_{3}$-Adrenoceptors and Altered Contractile Response to Inotropic Amines in Human Failing Myocardium. Circulation 103 (12), 1649-1655. doi:10.1161/01.CIR.103.12.1649

Monroe, R. G., and French, G. (1960). Ventricular Pressure-Volume Relationships and Oxygen Consumption in Fibrillation and Arrest. Circ. Res. 8, 260-266. doi:10.1161/01.res.8.1.260

Morales, D. R., Lipworth, B. J., Donnan, P. T., Jackson, C., and Guthrie, B. (2017). Respiratory Effect of Beta-Blockers in People with Asthma and Cardiovascular Disease: Population-Based Nested Case Control Study. BMC Med. 15 (1), 18. doi:10.1186/s12916-017-0781-0

Morelli, A., Ertmer, C., Westphal, M., Rehberg, S., Kampmeier, T., Ligges, S., et al. (2013). Effect of Heart Rate Control with Esmolol on Hemodynamic and Clinical Outcomes in Patients with Septic Shock: a Randomized Clinical Trial. Jama 310 (16), 1683-1691. doi:10.1001/jama.2013.278477

Morelli, A., Singer, M., Ranieri, V. M., D'Egidio, A., Mascia, L., Orecchioni, A., et al. (2016). Heart Rate Reduction with Esmolol Is Associated with Improved Arterial Elastance in Patients with Septic Shock: a Prospective Observational Study. Intensive Care Med. 42 (10), 1528-1534. doi:10.1007/ s00134-016-4351-2

Morelli, A., Whitehouse, T., and Rehberg, S. (2020). $\beta$-Blockade in Sepsis: Regulation of Persisting Sepsis-Related Tachycardia. Lancet Respir. Med. 8 (9), 833-834. doi:10.1016/S2213-2600(20)30063-1

Murry, J. S., Hoang, D. M., Barmparas, G., Harada, M. Y., Bukur, M., Bloom, M. B., et al. (2016). Prospective Evaluation of Early Propranolol after Traumatic Brain Injury. J. Surg. Res. 200 (1), 221-226. doi:10.1016/j.jss.2015.06.045

Mutlu, G. M., Dumasius, V., Burhop, J., McShane, P. J., Meng, F. J., Welch, L., et al. (2004). Upregulation of Alveolar Epithelial Active $\mathrm{Na}+$ Transport Is Dependent on Beta2-Adrenergic Receptor Signaling. Circ. Res. 94 (8), 1091-1100. doi:10.1161/01.Res.0000125623.56442.20
Mutlu, G. M., and Factor, P. (2008). Alveolar Epithelial Beta2-Adrenergic Receptors. Am. J. Respir. Cel Mol Biol 38 (2), 127-134. doi:10.1165/ rcmb.2007-0198TR

Myagmar, B. E., Flynn, J. M., Cowley, P. M., Swigart, P. M., Montgomery, M. D., Thai, K., et al. (2017). Adrenergic Receptors in Individual Ventricular Myocytes. Circulation Res. 120 (7), 1103-1115. doi:10.1161/ CIRCRESAHA.117.310520

Nademanee, K., Taylor, R., Bailey, W. E., Rieders, D. E., and Kosar, E. M. (2000). Treating Electrical Storm : Sympathetic Blockade versus Advanced Cardiac Life Support-Guided Therapy. Circulation 102 (7), 742-747. doi:10.1161/ 01.cir.102.7.742

Nguyen, M. N., Kiriazis, H., Ruggiero, D., Gao, X. M., Su, Y., Jian, A., et al. (2015). Spontaneous Ventricular Tachyarrhythmias in $\beta 2$-adrenoceptor Transgenic Mice in Relation to Cardiac Interstitial Fibrosis. Am. J. Physiol. Heart Circ. Physiol. 309 (5), H946-H957. doi:10.1152/ajpheart.00405.2015

Noveanu, M., Breidthardt, T., Reichlin, T., Gayat, E., Potocki, M., Pargger, H., et al. (2010). Effect of Oral $\beta$-blocker on Short and Long-Term Mortality in Patients with Acute Respiratory Failure: Results from the BASEL-II-ICU Study. Crit. Care 14 (6), R198. doi:10.1186/cc9317

Novotny, N. M., Lahm, T., Markel, T. A., Crisostomo, P. R., Wang, M., Wang, Y., et al. (2009). Beta-Blockers in Sepsis: Reexamining the Evidence. Shock 31 (2), 113-119. doi:10.1097/SHK.0b013e318180ffb6

Núñez-Villaveirán, T., Sánchez, M., Millán, P., and García-de-Lorenzo, A. (2015). Systematic Review of the Effect of Propanolol on Hypermetabolism in Burn Injuries. Med. Intensiva 39 (2), 101-113. doi:10.1016/j.medin.2014.08.002

O'Dwyer, M. J., Mankan, A. K., Stordeur, P., O'Connell, B., Duggan, E., White, M., et al. (2006). The Occurrence of Severe Sepsis and Septic Shock Are Related to Distinct Patterns of Cytokine Gene Expression. Shock 26 (6), 544-550. doi:10.1097/01.shk.0000235091.38174.8d

O’Gara, P. T., Kushner, F. G., Ascheim, D. D., Casey, D. E., Chung, M. K., de Lemos, J. A., et al. (2013). 2013 ACCF/AHA Guideline for the Management of ST-Elevation Myocardial Infarction. A Rep. Am. Coll. Cardiol. Foundation/ American Heart Assoc. Task Force Pract. Guidel. 61 (4), e78-e140. doi:10.1016/ j.jacc.2012.11.019

Orbegozo Cortes, D., Njimi, H., Dell'Anna, A. M., and Taccone, F. S. (2014). Esmolol for Septic Shock: More Than Just Heart Rate Control? Minerva Anestesiol 80 (2), 254-258.

Panchal, A. R., Bartos, J. A., Cabañas, J. G., Donnino, M. W., Drennan, I. R., Hirsch, K. G., et al. (2020). Part 3: Adult Basic and Advanced Life Support: 2020 American Heart Association Guidelines for Cardiopulmonary Resuscitation and Emergency Cardiovascular Care. Circulation 142(16_Suppl. 1_2), S366-S468. doi: doi:doi:10.1161/CIR.0000000000000916

Panchal, A. R., Berg, K. M., Kudenchuk, P. J., Del Rios, M., Hirsch, K. G., Link, M. S., et al. (2018). 2018 American Heart Association Focused Update on Advanced Cardiovascular Life Support Use of Antiarrhythmic Drugs during and Immediately after Cardiac Arrest: An Update to the American Heart Association Guidelines for Cardiopulmonary Resuscitation and Emergency Cardiovascular Care. Circulation 138 (23), e740-e749. doi:10.1161/ CIR.0000000000000613

Patel, M. B., McKenna, J. W., Alvarez, J. M., Sugiura, A., Jenkins, J. M., Guillamondegui, O. D., et al. (2012). Decreasing Adrenergic or Sympathetic Hyperactivity after Severe Traumatic Brain Injury Using Propranolol and Clonidine (DASH after TBI Study): Study Protocol for a Randomized Controlled Trial. Trials 13, 177. doi:10.1186/1745-6215-13-177

Patterson, A. J., Zhu, W., Chow, A., Agrawal, R., Kosek, J., Xiao, R. P., et al. (2004). Protecting the Myocardium: a Role for the Beta2 Adrenergic Receptor in the Heart. Crit. Care Med. 32 (4), 1041-1048. doi:10.1097/ 01.ccm.0000120049.43113.90

Plank, L. D., Connolly, A. B., and Hill, G. L. (1998). Sequential Changes in the Metabolic Response in Severely Septic Patients during the First 23 Days after the Onset of Peritonitis. Ann. Surg. 228 (2), 146-158. doi:10.1097/00000658199808000-00002

Preiser, J. C., Ichai, C., Orban, J. C., and Groeneveld, A. B. (2014). Metabolic Response to the Stress of Critical Illness. Br. J. Anaesth. 113 (6), 945-954. doi:10.1093/bja/aeu187

Prins, K. W., Neill, J. M., Tyler, J. O., Eckman, P. M., and Duval, S. (2015). Effects of Beta-Blocker Withdrawal in Acute Decompensated Heart Failure: A Systematic 
Review and Meta-Analysis. JACC Heart Fail. 3 (8), 647-653. doi:10.1016/ j.jchf.2015.03.008

Przkora, R., Barrow, R. E., Jeschke, M. G., Suman, O. E., Celis, M., Sanford, A. P., et al. (2006). Body Composition Changes with Time in Pediatric Burn Patients. J. Trauma 60 (5), 968-971. doi:10.1097/01.ta.0000214580.27501.19

Rassler, B. (2012). Contribution of $\alpha$ - and $\beta$-Adrenergic Mechanisms to the Development of Pulmonary Edema. Scientifica (Cairo) 2012, 829504. doi:10.6064/2012/829504

Rengo, G., Zincarelli, C., Femminella, G. D., Liccardo, D., Pagano, G., de Lucia, C., et al. (2012). Myocardial $\beta(2)$-adrenoceptor Gene Delivery Promotes Coordinated Cardiac Adaptive Remodelling and Angiogenesis in Heart Failure. Br. J. Pharmacol. 166 (8), 2348-2361. doi:10.1111/j.14765381.2012.01954.x

Rhodes, A., Evans, L. E., Alhazzani, W., Levy, M. M., Antonelli, M., Ferrer, R., et al. (2017). Surviving Sepsis Campaign: International Guidelines for Management of Sepsis and Septic Shock: 2016. Intensive Care Med. 43 (3), 304-377. doi:10.1097/CCM.000000000000225510.1007/s00134-017-4683-6

Rizoli, S. B., Jaja, B. N., Di Battista, A. P., Rhind, S. G., Neto, A. C., da Costa, L., et al. (2017). Catecholamines as Outcome Markers in Isolated Traumatic Brain Injury: the COMA-TBI Study. Crit. Care 21 (1), 37. doi:10.1186/s13054017-1620-6

Romana-Souza, B., Nascimento, A. P., and Monte-Alto-Costa, A. (2008). Low-dose Propranolol Improves Cutaneous Wound Healing of Burn-Injured Rats. Plast. Reconstr. Surg. 122 (6), 1690-1699. doi:10.1097/PRS.0b013e31818cbf67

Sakuma, T., Tuchihara, C., Ishigaki, M., Osanai, K., Nambu, Y., Toga, H., et al. (2001). Denopamine, a Beta(1)-Adrenergic Agonist, Increases Alveolar Fluid Clearance in Ex Vivo Rat and guinea Pig Lungs. J. Appl. Physiol. (1985) 90 (1), 10-16. doi:10.1152/jappl.2001.90.1.101985

Sander, O., Welters, I. D., Foëx, P., and Sear, J. W. (2005). Impact of Prolonged Elevated Heart Rate on Incidence of Major Cardiac Events in Critically Ill Patients with a High Risk of Cardiac Complications. Crit. Care Med. 33 (1), 81-82. doi:10.1097/01.Ccm.0000150028.64264.14

Sanfilippo, F., Santonocito, C., Morelli, A., and Foex, P. (2015). Beta-blocker Use in Severe Sepsis and Septic Shock: a Systematic Review. Curr. Med. Res. Opin. 31 (10), 1817-1825. doi:10.1185/03007995.2015.1062357

Schmittinger, C. A., Dünser, M. W., Haller, M., Ulmer, H., Luckner, G., Torgersen, C., et al. (2008). Combined Milrinone and Enteral Metoprolol Therapy in Patients with Septic Myocardial Depression. Crit. Care 12 (4), R99. doi:10.1186/ cc6976

Schroeppel, T. J., Fischer, P. E., Zarzaur, B. L., Magnotti, L. J., Clement, L. P., Fabian, T. C., et al. (2010). Beta-adrenergic Blockade and Traumatic Brain Injury: Protective? J. Trauma 69 (4), 776-782. doi:10.1097/TA.0b013e3181e981b8

Schroeppel, T. J., Sharpe, J. P., Magnotti, L. J., Weinberg, J. A., Clement, L. P., Croce, M. A., et al. (2014). Traumatic Brain Injury and $\beta$-blockers: Not All Drugs Are Created Equal. J. Trauma Acute Care Surg. 76 (2), 504-509. discussion 509. doi:10.1097/TA.0000000000000104

Shang, X., Wang, K., Xu, J., Gong, S., Ye, Y., Chen, K., et al. (2016). The Effect of Esmolol on Tissue Perfusion and Clinical Prognosis of Patients with Severe Sepsis: A Prospective Cohort Study. Biomed. Res. Int. 2016, 1038034. doi:10.1155/2016/1038034

Short, P. M., Williamson, P. A., Anderson, W. J., and Lipworth, B. J. (2013). Randomized Placebo-Controlled Trial to Evaluate Chronic Dosing Effects of Propranolol in Asthma. Am. J. Respir. Crit. Care Med. 187 (12), 1308-1314. doi:10.1164/rccm.201212-2206OC

Singer, K. E., Collins, C. E., Flahive, J. M., Wyman, A. S., Ayturk, M. D., and Santry, H. P. (2017). Outpatient Beta-Blockers and Survival from Sepsis: Results from a National Cohort of Medicare Beneficiaries. Am. J. Surg. 214 (4), 577-582. doi:10.1016/j.amjsurg.2017.06.007

Skrifvars, M. B., Pettilä, V., Rosenberg, P. H., and Castrén, M. (2003). A Multiple Logistic Regression Analysis of In-Hospital Factors Related to Survival at Six Months in Patients Resuscitated from Out-Of-Hospital Ventricular Fibrillation. Resuscitation 59 (3), 319-328. doi:10.1016/s0300-9572(03)00238-7

Song, D., Xu, J., Du, T., Yan, E., Hertz, L., Walz, W., et al. (2014). Inhibition of Brain Swelling after Ischemia-Reperfusion by $\beta$-adrenergic Antagonists: Correlation with Increased $\mathrm{K}+$ and Decreased Ca2+ Concentrations in Extracellular Fluid. Biomed. Res. Int. 2014, 873590. doi:10.1155/2014/873590

Stefan, M. S., Rothberg, M. B., Priya, A., Pekow, P. S., Au, D. H., and Lindenauer, P. K. (2012). Association between $\beta$-blocker Therapy and Outcomes in Patients
Hospitalised with Acute Exacerbations of Chronic Obstructive Lung Disease with Underlying Ischaemic Heart Disease, Heart Failure or Hypertension. Thorax 67 (11), 977-984. doi:10.1136/thoraxjnl-2012-201945

Suzuki, T., Morisaki, H., Serita, R., Yamamoto, M., Kotake, Y., Ishizaka, A., et al. (2005). Infusion of the Beta-Adrenergic Blocker Esmolol Attenuates Myocardial Dysfunction in Septic Rats. Crit. Care Med. 33 (10), 2294-2301. doi:10.1097/01.ccm.0000182796.11329.3b

Suzuki, T., Suzuki, Y., Okuda, J., Kurazumi, T., Suhara, T., Ueda, T., et al. (2017). Sepsis-induced Cardiac Dysfunction and $\beta$-adrenergic Blockade Therapy for Sepsis. J. Intensive Care 5, 22. doi:10.1186/s40560-017-0215-2

Tan, K., Harazim, M., Tang, B., Mclean, A., and Nalos, M. (2019). The Association between Premorbid Beta Blocker Exposure and Mortality in Sepsis-A Systematic Review. Crit. Care 23 (1), 298. doi:10.1186/s13054019-2562-y

Tripathi, F. M., Guha, S., Khanna, N. N., Chansoria, J. P. N., Sinha, J. K., and Udupa, K. N. (1981). Plasma Catecholamines in thermal burns. Burns 8 (2), 99-101. doi:10.1016/0305-4179(81)90029-2

Thrush, D. N., Downs, J. B., and Smith, R. A. (1997). Is Epinephrine Contraindicated During Cardiopulmonary Resuscitation? Circulation 96 (8), 2709-2714. doi:10.1161/01.CIR.96.8.2709

Umehara, S., Goyagi, T., Nishikawa, T., Tobe, Y., and Masaki, Y. (2010). Esmolol and Landiolol, Selective Beta1-Adrenoreceptor Antagonists, Provide Neuroprotection against Spinal Cord Ischemia and Reperfusion in Rats. Anesth. Analg 110 (4), 1133-1137. doi:10.1213/ ANE.0b013e3181cdb06b

Van Herpen, C. H., van Blokland, D. A., and van Zanten, A. R. H. (2019). Metabolic effects of beta-blockers in critically ill patients: A retrospective cohort study. Heart Lung 48 (4), 278-286. doi:10.1016/ j.hrtlng.2019.02.004

Wachter, S. B., and Gilbert, E. M. (2012). Beta-adrenergic Receptors, from Their Discovery and Characterization through Their Manipulation to Beneficial Clinical Application. Cardiology 122 (2), 104-112. doi:10.1159/ 000339271

Walkey, A. J., Evans, S. R., Winter, M. R., and Benjamin, E. J. (2016). Practice Patterns and Outcomes of Treatments for Atrial Fibrillation during Sepsis: A Propensity-Matched Cohort Study. Chest 149 (1), 74-83. doi:10.1378/chest.150959

Wang, S., Li, M., Duan, J., Yi, L., Huang, X., Chen, D., et al. (2017). [Effect of Esmolol on Hemodynamics and Clinical Outcomes in Patients with Septic Shock]. Zhonghua Wei Zhong Bing Ji Jiu Yi Xue 29 (5), 390-395. doi:10.3760/ cma.j.issn.2095-4352.2017.05.002

Wang, Z., Wu, Q., Nie, X., Guo, J., and Yang, C. (2015). Combination Therapy with Milrinone and Esmolol for Heart protection in Patients with Severe Sepsis: a Prospective, Randomized Trial. Clin. Drug Investig. 35 (11), 707-716. doi:10.1007/s40261-015-0325-3

Williams, F. N., Herndon, D. N., Kulp, G. A., and Jeschke, M. G. (2011). Propranolol Decreases Cardiac Work in a Dose-dependent Manner in Severely Burned Children. Surgery 149 (2), 231-239. doi:10.1016/ j.surg.2010.05.015

Wilmore, D. W., Long, J. M., Mason, A. D., Skreen, R. W., and Pruitt, B. A. (1974). Catecholamines: Mediator of the Hypermetabolic Response to Thermal Injury. Ann. Surg. 180 (4), 653-669. doi:10.1097/00000658-197410000-00031

Wittstein, I. S., Thiemann, D. R., Lima, J. A., Baughman, K. L., Schulman, S. P., Gerstenblith, G., et al. (2005). Neurohumoral Features of Myocardial Stunning Due to Sudden Emotional Stress. N. Engl. J. Med. 352 (6), 539-548. doi:10.1056/ NEJMoa043046

Wortsman, J., Frank, S., and Cryer, P. E. (1984). Adrenomedullary Response to Maximal Stress in Humans. Am. J. Med. 77 (5), 779-784. doi:10.1016/00029343(84)90512-6

Writing, C., Maddox, T. M., Januzzi, J. L., Jr., Allen, L. A., Breathett, K., Butler, J., et al. (2021). 2021 Update to the 2017 ACC Expert Consensus Decision Pathway for Optimization of Heart Failure Treatment: Answers to 10 Pivotal Issues about Heart Failure with Reduced Ejection Fraction: A Report of the American College of Cardiology Solution Set Oversight Committee. J. Am. Coll. Cardiol. 77 (6), 772-810. doi:10.1016/j.jacc.2020.11.022

Xinqiang, L., Weiping, H., Miaoyun, W., Wenxin, Z., Wenqiang, J., Shenglong, C., et al. (2015). [Esmolol Improves Clinical Outcome and Tissue Oxygen Metabolism in Patients with Septic Shock through 
Controlling Heart Rate]. Zhonghua Wei Zhong Bing Ji Jiu Yi Xue 27 (9), 759-763.

Yang, N., Shi, X. L., Zhang, B. L., Rong, J., Zhang, T. N., Xu, W., et al. (2018). The Trend of $\beta 3$-Adrenergic Receptor in the Development of Septic Myocardial Depression: A Lipopolysaccharide-Induced Rat Septic Shock Model. Cardiology 139 (4), 234-244. doi:10.1159/000487126

Yang, S., Liu, Z., Yang, W., Zhang, G., Hou, B., Liu, J., et al. (2014). [Effects of the $\beta$-blockers on Cardiac protection and Hemodynamics in Patients with Septic Shock: a Prospective Study]. Zhonghua Wei Zhong Bing Ji Jiu Yi Xue 26 (10), 714-717. doi:10.3760/cma.j.issn.2095-4352.2014.10.007

Zangbar, B., Khalil, M., Rhee, P., Joseph, B., Kulvatunyou, N., Tang, A., et al. (2016). Metoprolol Improves Survival in Severe Traumatic Brain Injury Independent of Heart Rate Control. J. Surg. Res. 200 (2), 586-592. doi:10.1016/j.jss.2015.08.020

Zhang, X. J., Meng, C., Chinkes, D. L., Finnerty, C. C., Aarsland, A., Jeschke, M. G., et al. (2009). Acute Propranolol Infusion Stimulates Protein Synthesis in Rabbit Skin Wound. Surgery 145 (5), 558-567. doi:10.1016/j.surg.2009.01.006
Conflict of Interest: The authors declare that the research was conducted in the absence of any commercial or financial relationships that could be construed as a potential conflict of interest.

Publisher's Note: All claims expressed in this article are solely those of the authors and do not necessarily represent those of their affiliated organizations, or those of the publisher, the editors and the reviewers. Any product that may be evaluated in this article, or claim that may be made by its manufacturer, is not guaranteed or endorsed by the publisher.

Copyright $\odot 2021$ Bruning, Dykes, Jones, Wayne and Sikora Newsome. This is an open-access article distributed under the terms of the Creative Commons Attribution License (CC BY). The use, distribution or reproduction in other forums is permitted, provided the original author(s) and the copyright owner(s) are credited and that the original publication in this journal is cited, in accordance with accepted academic practice. No use, distribution or reproduction is permitted which does not comply with these terms. 